Marquette University

e-Publications@Marquette

$1-1-2010$

\title{
Anion Exchange Kinetics of Nanodimensional Layered Metal Hydroxides: Use of Isoconversional Analysis
}

Stephen Majoni

Marquette University

Jeanne Hossenlopp

Marquette University, jeanne.hossenlopp@marquette.edu

Accepted version. Journal of Physical Chemistry A, Volume 114, No. 49 (2010): 12858-12869. DOI.

(C) 2010 American Chemical Society. Used with permission. 


\title{
Anion Exchange Kinetics of Nanodimensional Layered Metal Hydroxides: Use of Isoconversional Analysis
}

\author{
Stephen Majoni \\ Department of Chemistry, Marquette University, \\ Milwaukee, WI \\ Jeanne M. Hossenlopp \\ Department of Chemistry, Marquette University, \\ Milwaukee, WI
}

Journal of Physical Chemistry A, Vol 114, No. 49 (December 16, 2010): pg. 12858-12869. DOI. This article is (c) American Chemical Society and permission has been granted for this version to appear in e-Publications@Marquette. American Chemical Society does not grant permission for this article to be further copied/distributed or hosted elsewhere without the express permission from American Chemical Society. 


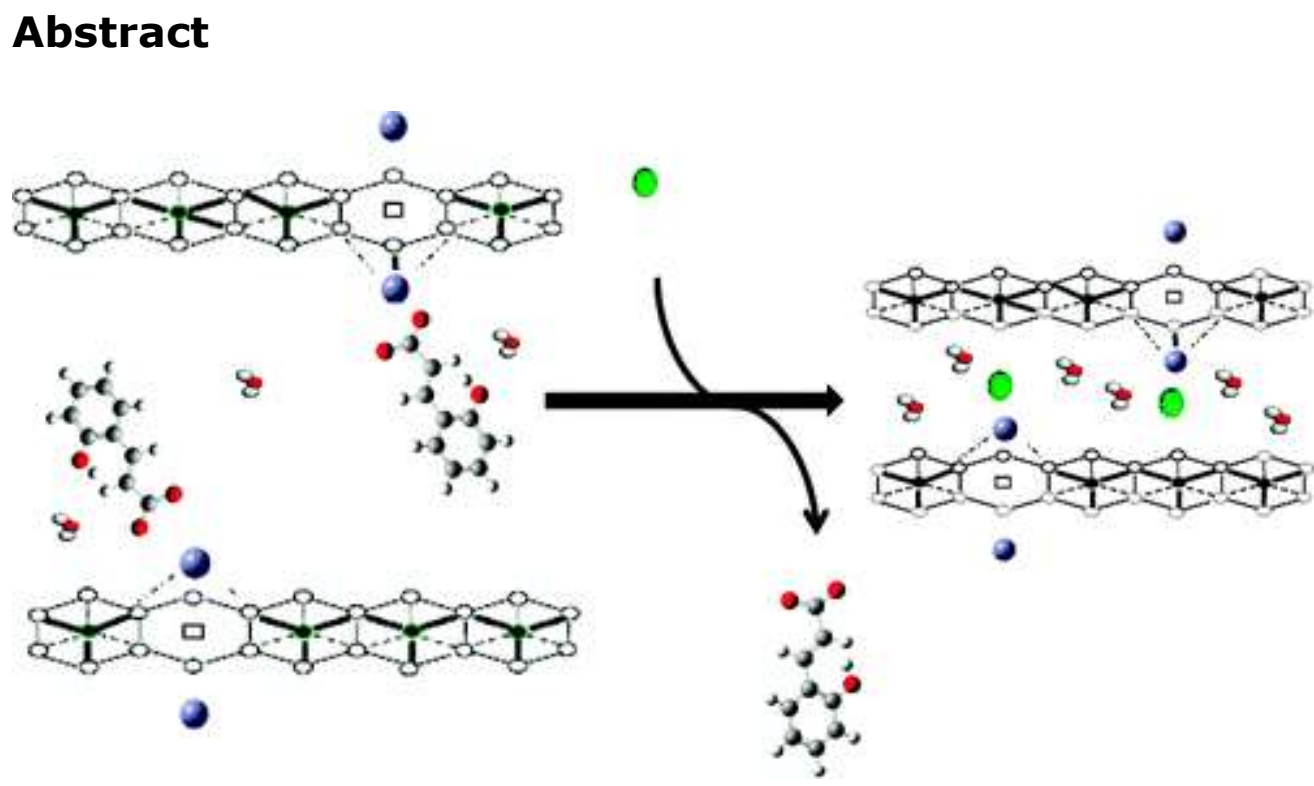

Anion exchange reactions of nanodimensional layered metal hydroxide compounds are utilized to create materials with targeted physical and chemical properties and also as a means for controlled release of intercalated anions. The kinetics of this important class of reaction are generally characterized by model-based approaches. In this work, a different approach based on isothermal, isoconversional analysis was utilized to determine effective activation energies with respect to extent of reaction. Two different layered metal hydroxide materials were chosen for reaction with chloride anions, using a temperature range of $30-60^{\circ} \mathrm{C}$. The concentrations of anions released into solution and the changes in polycrystalline solid phases were evaluated using model-based (Avrami-Erofe'ev nucleation-growth model) and model-free (integral isoconversional) methods. The results demonstrate the utility of the isoconversional approach for identifying when fitting to a single model is not appropriate, particularly for characterizing the temperature dependence of the reaction kinetics.

\section{Introduction}

Layered metal hydroxides with exchangeable interlayer anions can be utilized to provide nanodimensional structures with tunable physical and chemical properties. This has resulted in these materials being used in flame retardadation, $\underline{1,2}$ ion-exchange, magnetism, and catalysis, $\frac{3-6}{-}$ and as hosts for drugs, herbicides, and plant regulators. $\frac{7-10}{-10}$ Examples of these materials include layered double hydroxides (LDHs) $\left[\mathrm{M}^{2+}{ }_{1-x} \mathrm{M}^{3+}{ }_{x}(\mathrm{OH})_{2}\right] \mathrm{A}^{n-}{ }_{x / n} \cdot y \mathrm{H}_{2} \mathrm{O}$, hydroxy double salts (HDSs) $\left[\left(\mathrm{M}^{2+}{ }_{1-}\right.\right.$ $\left.{ }_{x} \mathrm{Me}^{2+}{ }_{1+x}\right)(\mathrm{OH})_{3(1-y) / n]} \mathrm{A}^{n-}{ }_{(1+3 y) / n} \cdot \mathrm{mH}_{2} \mathrm{O}$ where $\mathrm{M}^{2+}$ and $\mathrm{Me}^{2+}$ represent different divalent metal ions, and layered hydroxy salts (LHSs) 
containing a single divalent metal ion. In all these materials $A^{n-}$ is an exchangeable charge compensating anion of charge $n$ which controls the interlayer space. The LDH layers have a brucite $\left\{\mathrm{Mg}(\mathrm{OH})_{2}\right\}$ type structure in which metal ions are surrounded by six hydroxide ions in an approximately octahedral geometry. $\frac{11}{}$ HDSs form similar structures, in some cases with unoccupied metal ion sites in the metal hydroxide layer, and tetrahedrally coordinated metal ions situated above and below the vacant sites. $\frac{12}{}$ Anion exchange reactions of layered metal hydroxides are useful for creating materials with optimal physicochemical properties for targeted applications, making the characterization of exchange kinetics of practical interest. In addition, understanding the factors that control release of functional anions from these structures is important in designing hosts for storage and triggered release. $\underline{7}$ Perhaps the most widely utilized approach for evaluating kinetics of this class of reactions has been the use of the Avrami-Erofe'ev nucleation-growth model. $\underline{13,14}$ In this model, the extent of reaction $(a)$ is scaled from zero at the start of the reaction to one at the end, and depends upon the rate constant, $k$, and a coefficient, $n$, as shown in eq $\underline{1}$.

$$
a(t)=1-e^{\left[-(k t)^{n]}\right]}
$$

The coefficient $n$ potentially contains information about the mechanism of the reaction and is often used to evaluate whether the reaction rate is controlled by diffusion or by nucleation and provides information on the dimension of growth. $\frac{15}{1}$ eq $\underline{1}$ can be linearized by taking the natural logarithms twice obtaining eq $\underline{2}$.

$$
\ln [-\ln (1-\alpha)]=n \ln (t)+n \ln (k)
$$

The double-logarithmic plot of $\ln [-\ln (1-a)]$ as a function of In $t$ gives a linear plot in which the value of $n$ is obtained from the slope and the value of $k$ is evaluated from the intercept. Although double-logarithmic plots have been used since the $1950 \mathrm{~s}, \underline{16}$ they were made popular by Sharp and Hancock in 1972. $\frac{17}{}$ For reactions with different mechanisms, the double-logarithmic plots will have different slopes making it easy to distinguish reactions occurring via different mechanisms. $\frac{18}{16}$ The Avrami-Erofe'ev model has been applied successfully to a wide range of reactions which includes crystallization 
and phase transformations in glasses and alloys, metal hydrogenation reactions, $\underline{19}$ crystallization and growth of polymers, $\underline{20}$ and in anion exchange reactions of layered materials. $\underline{15,21,22}$

However, this model-based approach is of limited use in cases where there are structural changes occurring during the exchange process. Although periods with different mechanisms can be distinguished in a double-logarithmic plot, obtaining an effective activation energy that can be utilized to describe the temperature dependence over the entire course of the reaction becomes difficult. $\underline{18}$ The Avrami-Erofe'ev model works well in some cases but is not sufficient when the mechanism is not constant over the entire extent of reaction and generally is used to fit to the data in a limited range $0.15<a<0.85 \cdot 15,21$ The reliability of the Arrhenius parameters obtained from these model fitting procedures is subject to the proper choice of the reaction model. $\underline{23,24}$

A strategy utilized in thermal analysis studies to identify when fitting to a single model is not an appropriate strategy is to utilize isoconversional methods as proposed by Vyazovkin and Wight. $\underline{25}$ Isoconversional methods have been applied successfully in a variety of reactions and allow for the determination of effective activation energies $\left(E_{\mathrm{a}}\right)$ for reactions which involve multiple steps which may reflect more than one mechanistic contribution. $\underline{26,27}$ The determination of how $E_{a}$ varies as a function of the extent of reaction (a), provides information about the changes in reaction mechanism and enables the investigation of reaction mechanisms. $\underline{26,28}$ When a single process is involved, the $E_{\mathrm{a}}$ is constant over the conversion range; changes in $E_{\mathrm{a}}$ as a function of extent of reaction reflect changing contributions of individual processes involved in the reaction. For isothermal processes, isoconversional methods can be divided into differential methods (eq 3) and integral method (eqs 4). $\underline{26,29}$

$$
\begin{gathered}
\ln \frac{d \alpha}{d t}=\ln [A f(\alpha)]-\frac{E_{\mathrm{a}}}{R T} \\
\ln t=\ln \frac{g(\alpha)}{A}+\frac{E_{\mathrm{a}}}{R T}
\end{gathered}
$$


NOT THE PUBLISHED VERSION; this is the author's final, peer-reviewed manuscript. The published version may be accessed by following the link in the citation at the bottom of the page.

In eqs $\underline{3}$ and $\underline{4}, E_{\mathrm{a}}$, and $\mathrm{a}$ are as defined before, $A$ is the preexponential factor, $t$ is the time, $T$ the temperature, $R$ is the gas constant, $f(a)$ and $g(a)$ are the reaction model and the integral reaction model respectively. The isoconversional approach has been widely applied in the degradation kinetics of a variety of materials which include polymers and inorganic molecules, recently the approach has been extended to other reactions which include hydride formation in reactive plasmas. $\underline{30}$

In this work, we report the use of isothermal, isoconversional analysis to examine the anion exchange kinetics of two model reactions which have been chosen to illustrate how the isoconversional approach can be exploited to identify when model-based approaches such as Avrami-Erofe'ev kinetics, are appropriate. The selected examples involve release of cinnamate or hydroxycinnamate anions from HDS and LHS structures via exchange with chloride anions. Isoconversional analysis is applied to evaluate the rate of anion release into solution as well as changes in solid state structure in order to derive effective activation energies that can be compared to global $E_{a}$ values obtained from the Avrami-Erofe'ev model fitting method.

\section{Experimental Methods}

\subsection{Materials}

Copper nitrate trihydrate $\left[\mathrm{Cu}\left(\mathrm{NO}_{3}\right)_{2} \cdot 3 \mathrm{H}_{2} \mathrm{O}\right](98.0 \%)$ and copper acetate monohydrate $\left[\mathrm{Cu}\left(\mathrm{C}_{2} \mathrm{H}_{3} \mathrm{O}_{2}\right)_{2} \cdot \mathrm{H}_{2} \mathrm{O}\right.$ ] $(98.0 \%)$ were obtained from Alfa Aesar, trans-cinnamic acid $\left[\mathrm{C}_{6} \mathrm{H}_{5} \mathrm{CHCHCO}_{2} \mathrm{H}\right]$, and trans-ohydroxycinnamic acid $\left[0-(\mathrm{OH}) \mathrm{C}_{6} \mathrm{H}_{4} \mathrm{CHCHCO}_{2} \mathrm{H}\right](98 \%)$, were obtained from Sigma Aldrich Chemical Co. Sodium chloride (100\%) and zinc oxide $(100 \%)$ were obtained from J. T. Baker. Sodium hydroxide (pellets, 98\%) was obtained from EMD Chemicals. All materials were used as supplied by manufacturer without further purification. 2.2 Synthesis of Hydroxy Double Salts and Layered Hydroxy Salts Precursor layered hydroxy salts (LHSs) and hydroxy double salts (HDSs) were prepared according to literature methods. $\underline{21,31,32}$ Basic copper nitrate (BCN) was prepared via a titration method; a $0.4 \mathrm{M}$ copper nitrate solution was slowly titrated, under continuous stirring, with a $0.1 \mathrm{M} \mathrm{NaOH}$ solution until the ratio $\mathrm{Cu}^{2+}: \mathrm{OH}^{-}$of $1: 1.5$ was 
achieved. Zinc copper hydroxy acetate (ZC-Ac) was prepared by adding $0.41 \mathrm{~g}$ of $\mathrm{ZnO}$ to $1.00 \mathrm{~g}$ of $\mathrm{Cu}\left(\mathrm{CH}_{3} \mathrm{COO}\right)_{2} \cdot \mathrm{H}_{2} \mathrm{O}$ in $10 \mathrm{~mL}$ of deionized (DI) water with vigorous stirring at room temperature. The resultant precipitates were filtered, washed several times with DI water, and dried at room temperature.

Copper hydroxy-o-hydroxycinnamate (C-o-HCn) and zinc copper hydroxy cinnamate ( $Z C-C n)$ were prepared by anion exchange with the conditions for exchange being optimized for each material. The structures of the $\mathrm{o}-\mathrm{HCn}$ and $\mathrm{Cn}$ anions used in this study are shown in Figure $\underline{1}$. To improve solubility in water, the acids (o-hydroxycinnamic acid and cinnamic acid) were reacted with an equimolar amount of $\mathrm{NaOH}$ in enough deionized water to produce the desired concentration for complete exchange of the precursor anion without observable degradation of the layered material. $20.0 \mathrm{~g}$ of BCN was mixed with $1000 \mathrm{~cm}^{3}$ of $0.08 \mathrm{M} \mathrm{o}$-hydroxycinnamate $(\mathrm{o}-\mathrm{HCn})$ solution at room temperature for $48 \mathrm{~h}$ with frequent stirring. The sample was filtered and the exchange reaction repeated twice with fresh $\mathrm{O}-\mathrm{HCn}$ solutions in order to get complete exchange to form the $\mathrm{C}-\mathrm{O}-\mathrm{HCn}$ product. 20.0 $\mathrm{g}$ of ZC-Ac was mixed with $1000 \mathrm{~cm}^{3}$ of $1.0 \mathrm{M}$ cinnamate $(\mathrm{Cn})$ and allowed to react at room temperature, with frequent stirring, for $8 \mathrm{~h}$ to produce the ZC-Cn product; longer reaction times led to degradation of the layered metal hydroxide. Elemental analysis of precursor and product layered metal hydroxides was performed by Huffman Laboratories, Colorado, using atomic emission spectroscopy interfaced with inductively coupled plasma (AES-ICP) for determination of metals.

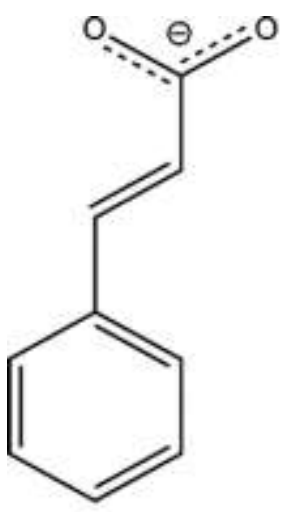

(a)

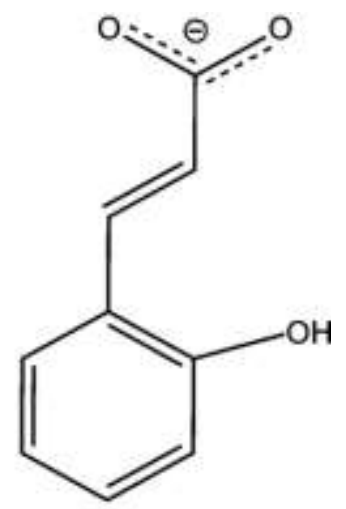

(b)

Figure 1. Structure of the anions used in this study: (a) cinnamate $(\mathrm{Cn}),(\mathrm{b}) \mathrm{O}^{-}$ hydroxycinnamate $(\mathrm{o}-\mathrm{HCn})$.

Journal of Physical Chemistry A, Vol 114, No. 49 (December 16, 2010): pg. 12858-12869. DOI. This article is (C) American Chemical Society and permission has been granted for this version to appear in e-Publications@Marquette. American Chemical Society does not grant permission for this article to be further copied/distributed or hosted elsewhere without the express permission from American Chemical Society. 
NOT THE PUBLISHED VERSION; this is the author's final, peer-reviewed manuscript. The published version may be accessed by following the link in the citation at the bottom of the page.

\subsubsection{Exchange Kinetics}

The replacement of $\mathrm{Cn}$ or $\mathrm{o}-\mathrm{HCn}$ anions by chloride ions as guest anions was investigated in the temperature range 30 to $60^{\circ} \mathrm{C}$. The exchange reactions were performed in a shaking water bath with a temperature stability of $\pm 0.2^{\circ} \mathrm{C}$ and shaking speed of 300 strokes per minute. Multiple reaction samples were prepared by mixing $0.15 \mathrm{~g}$ of $\mathrm{C}-\mathrm{o}-\mathrm{HCn}$ or ZC-Cn with $15 \mathrm{~mL}$ of $1.0 \mathrm{M}$ sodium chloride; samples were continuously agitated in the water bath for a specified time period. After the specified time period, the reaction was quenched by filtration followed by washing of the residue several times with DI water. Solid samples were allowed to dry in air at room temperature prior to analysis. The concentration of released anions at specific time periods was monitored by UV-vis analysis on a Perkin-Elmer Lambda 35 UV-vis Spectrophotometer using quartz cuvettes with a path length of $1 \mathrm{~cm}$. Representative UV-vis spectra are shown in Supporting Information Figure $\underline{\mathrm{S} 1}$ and anions concentrations were monitored at the peak of the UV band ( $\mathrm{Cn}, \lambda_{\max }=269 \mathrm{~nm}$ and $o-\mathrm{HCn}, \lambda_{\max }=270$ $\mathrm{nm}$ ). Calibration curves for calculating (hydroxy) cinnamate concentration in aqueous solutions were determined in the presence of sodium chloride concentrations identical to those used in the exchange reactions. The concentrations of released (hydroxy) cinnamate anions at time $t, C_{t}$, and the concentration at equilibrium, $\mathrm{C}_{\infty}$, were used to calculate the extent of reaction using eq $\underline{5}$.

$$
\alpha=\frac{C_{t}}{C_{\infty}}
$$

For solid state transformation, the intensity of a given Bragg reflection was obtained by fitting the XRD peaks to a Gaussian or Lorentzian function. The disappearance of the (001) reflection of the host anion phase as well as the growth of the (001) reflection of chloride phase were monitored and the relative intensities of the host phase were used to calculate the extent of reaction for the decay of the host phase ( $a_{\text {host }}$ ) at time $(t)$ based on eq $\underline{6}$. 
NOT THE PUBLISHED VERSION; this is the author's final, peer-reviewed manuscript. The published version may be accessed by following the link in the citation at the bottom of the page.

$$
\alpha_{\mathrm{host}(t)}=\left[\frac{1-\left(\frac{I_{\mathrm{h}(t)}}{I_{\mathrm{g}(t)}+I_{\mathrm{h}(t)}}\right)}{1-\left(\frac{I_{\mathrm{h}(\infty)}}{I_{\mathrm{g}(\infty)}+I_{\mathrm{h}(\infty)}}\right)}\right]
$$

In eq $\underline{6}, I_{\mathrm{h}(t)}$ is the intensity of a given Bragg reflection of the host anion at time $t, I_{g(t)}$ is the intensity of a given Bragg reflection of the guest anion at time $t_{1} I_{\mathrm{h}(\infty)}$ is the equilibrium intensity of the Bragg reflection of the host anion (determined at equilibrium) and $I_{g(\infty)}$ is the equilibrium intensity of the Bragg reflection of the guest anion (determined at equilibrium).

\subsection{FTIR, Thermogravimetric Analysis and Powder X- ray Diffraction of Solids}

Fourier transform infrared (FTIR) spectra of the layered materials were obtained on a Perkin-Elmer Spectrum 100 FT-IR spectrometer operated at a $2 \mathrm{~cm}^{-1}$ resolution in the $4000-650 \mathrm{~cm}^{-1}$ spectral range; 16 scans were averaged. The FTIR spectra were recorded using a single reflection ATR accessory with a ZnSe prism (PIKE MIRacle, from PIKE technology). Powder X-ray diffraction (PXRD) measurements were recorded on a Rigaku Miniflex II diffractometer using $\mathrm{Cu} \mathrm{Ka}(\lambda=1.54 \AA)$ radiation source at $30 \mathrm{kV}$ and $15 \mathrm{~mA}$. The patterns were recorded in the $2 \theta$ range of $2.0^{\circ}-45.0^{\circ}$; data acquisition was performed using a step size of $0.0167^{\circ}$ per second. The powder samples were pressed in to the trough of glass sample holders, the diffractometer was calibrated using a silicon reference material (RSRP-43275G: manufactured by Rigaku Corporation). Thermogravimetric analysis (TGA) was performed on a Netzsch TG 209 F1, TGA instrument. Samples with a weight of $10.0 \pm$ $0.2 \mathrm{mg}$ were placed into aluminum oxide crucibles and heated under a constant flow of nitrogen at a heating rate of $20^{\circ} \mathrm{C} \mathrm{min}-1$ between 40 and $800^{\circ} \mathrm{C}$.

\subsection{Chain Length Calculation}

The size of the nitrate anion and the chain length of $\mathrm{Cn}$ and $o^{-}$ $\mathrm{HCn}$ anions were calculated utilizing the Gaussian 98 program ${ }^{33}$ and

Journal of Physical Chemistry A, Vol 114, No. 49 (December 16, 2010): pg. 12858-12869. DOI. This article is (C) American Chemical Society and permission has been granted for this version to appear in e-Publications@Marquette. American Chemical Society does not grant permission for this article to be further copied/distributed or hosted elsewhere without the express permission from American Chemical Society. 
carried out at the DFT (B3LYP) level of theory with $6-311++G(d, p)$ basis set. The chain length was calculated as the interatomic distance between the carboxyl oxygen and the furthest hydrogen atom.

\section{Results and Discussion}

\section{1 Characterization of Precursor LHS and HDS}

PXRD results for $B C N$, which has been indexed as the synthetic monoclinic gerhardtite $\mathrm{Cu}_{2}(\mathrm{OH})_{3} \mathrm{NO}_{3}$, space group $P 2_{1} / m(4)$, (PDF \# $45-594), \underline{34}$ are shown in Figure $\underline{2} A$. The formula of gerhardtite is in close agreement with the formula obtained from elemental analysis $\left\{\mathrm{Cu}_{2.3}(\mathrm{OH})_{3.6}\left(\mathrm{NO}_{3}\right)\right\}$, the elemental analysis results are shown in Table $\underline{\mathrm{S} 1}$ in the Supporting Information. Figure $\underline{2} \mathrm{~A}$ shows the PXRD patterns for BCN (lower panel) and its exchange product (upper panel). In both cases, the materials show intense 00 / reflections which are equally spaced indicating that the structures are layered and possess high range ordering, at least to the third order in the $c$ axis direction. The 001-003 Bragg reflections were used to calculate the basal spacing of $B C N$ using the Bragg equation, $\underline{35}$ the obtained value of $6.94 \pm 0.01 \AA$ matches literature value of $6.81 \AA$. 36 Upon exchanging nitrate with 0 $\mathrm{HCn}$, new peaks appear at lower $2 \theta$ values (001-003) giving an average $d$-spacing value of $16.813 \pm 0.003 \AA$; this is an indication of the expansion of the interlayer space. The increase of the interlayer space, from $6.94 \AA$ in $\mathrm{BCN}$ to $16.81 \AA$ in $\mathrm{C}-\mathrm{O}-\mathrm{HCn}$, is consistent with a smaller nitrate anion ( $1.95 \AA$ ) being replaced by a larger $\mathrm{o}-\mathrm{HCn}$ anion (chain length $=8.63 \AA$ ). The $\mathrm{o}-\mathrm{HCn}$ anions are either tilted or partially interdigitated within the metal hydroxide layers. The absence of nitrate ion reflections from the $\mathrm{C}-\mathrm{O}-\mathrm{HCn}$ trace indicates that the exchange was complete; this is consistent with elemental analysis results (Table $\underline{\mathrm{S} 1}$ in the Supporting Information). The metal ion to anion ratios are consistent, within approximately $10 \%$, for a nearly $1: 1$ exchange. 
NOT THE PUBLISHED VERSION; this is the author's final, peer-reviewed manuscript. The published version may be accessed by following the link in the citation at the bottom of the page.
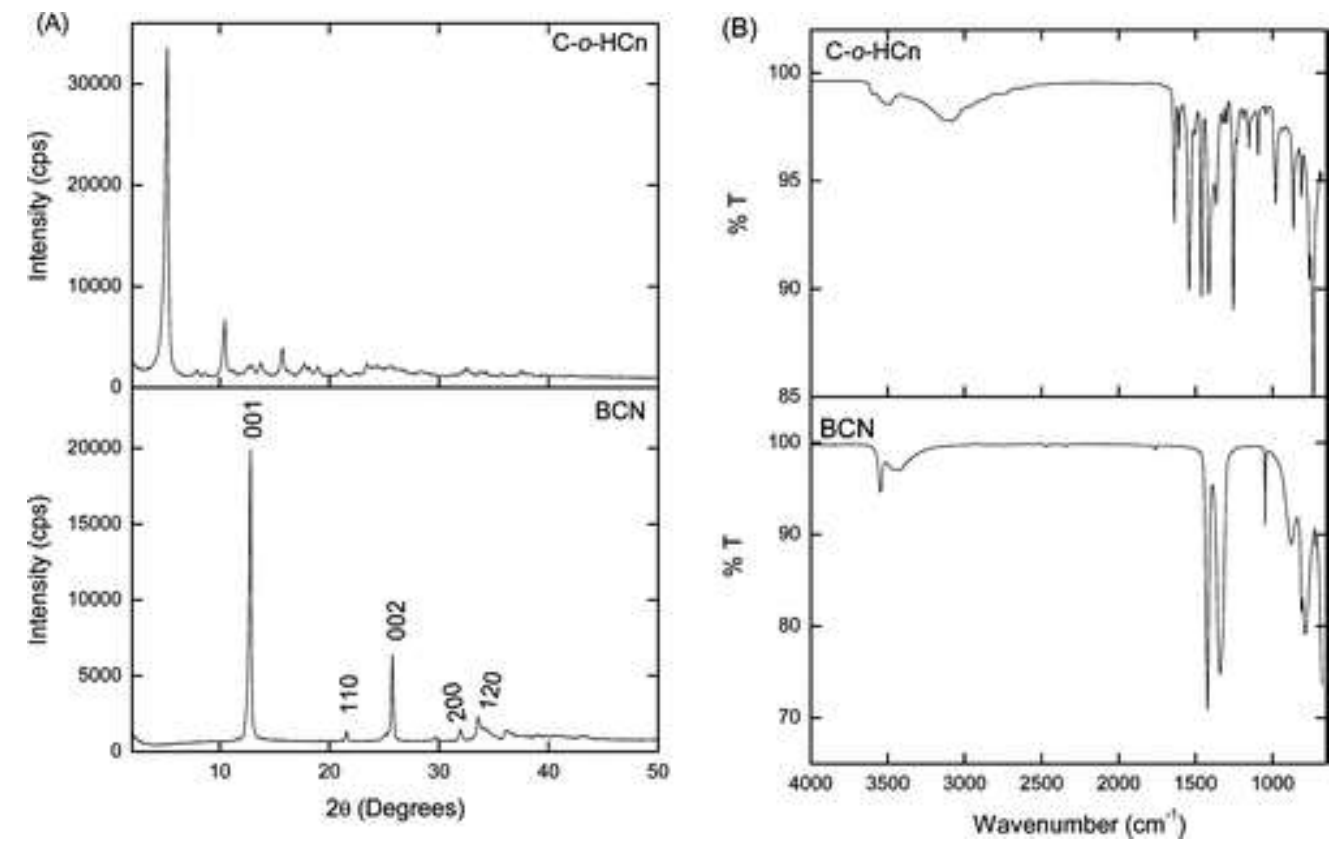

Figure 2. (A) PXRD profiles for $B C N$ and $C-O-H C n$ and (B) FTIR spectra for $B C N$ and $C-$ o-HCn.

FTIR spectra of BCN (lower panel) and C-o-HCn (upper panel) are shown in Figure $2 \mathrm{~B}$. Vibrational frequencies of $\mathrm{BCN}$ are in agreement with those obtained by other workers and have been assigned as follows; $1049 \mathrm{~cm}^{-1}, \mathrm{~N}-\mathrm{O}$ stretching $\left(\mathrm{v}_{2}\right) ; 1338 \mathrm{~cm}^{-1}, \mathrm{O}-$ $\mathrm{NO}_{2}$ symmetric stretch $\left(\mathrm{V}_{1}\right) ; 1425 \mathrm{~cm}^{-1}, \mathrm{O}-\mathrm{NO}_{2}$ asymmetric stretch $\left(\mathrm{V}_{4}\right) . \frac{36,37}{}$ The presence of two $\mathrm{O}-\mathrm{NO}_{2}$ peaks is consistent with vibrations of coordinated nitrate groups of $C_{2 v}$ symmetry. Coordination of the nitrate group to the matrix copper ion through one of the oxygen atoms reduces the symmetry of the nitrate ion from $D_{3 h}$ in free nitrate to $C_{2 v}$ resulting in splitting of the doubly degenerate $\mathrm{NO}_{2}$ stretch $\left(v_{3}\right.$, $1360-1380 \mathrm{~cm}^{-1}$ ) in free nitrate. $\frac{37}{.}$

A set of new peaks appear in the exchange product corresponding to the presence of $\mathrm{o}-\mathrm{HCn}$ in the gallery and the nitrate vibrational peaks disappeared, indicating complete exchange which is in agreement with PXRD results and elemental analysis results. The new peaks appear at $1639 \mathrm{~cm}^{-1}(C=C$ bond vibration of the $a, \beta-$ unsaturated carboxylate group), $1540 \mathrm{~cm}^{-1}$ and $1417 \mathrm{~cm}^{-1}$ (Vasym $\mathrm{C}=0$ and $\mathrm{v}_{\text {sym }} \mathrm{C}=\mathrm{O}$, respectively). There is extensive hydrogen bonding in $\mathrm{C}$ $\mathrm{o}-\mathrm{HCn}$ as indicated by the appearance of broad peaks and the disappearance of the sharp peak in the $\mathrm{OH}$ stretching region 
$\left(3650-3000 \mathrm{~cm}^{-1}\right.$ ). Thermogravimetric analysis (Figure $\underline{\mathrm{S}}$ ) and elemental analysis results (Table $\underline{\mathrm{S} 1}$ ), provided as Supporting Information, demonstrate that the BCN precursor does not have a significant amount of intercalated water, whereas $\mathrm{C}-\mathrm{O}-\mathrm{HCn}$ does contain some associated water molecules which may reside within the interlayer space. The appearance of broad absorption peaks in $\mathrm{C}-\mathrm{O}$ $\mathrm{HCn}$ may be due to the presence of interlayer water molecules which formed hydrogen bonds with free layer hydroxyl groups or $\mathrm{o}-\mathrm{HCn}$ molecules. Broad absorption bands in the $\mathrm{OH}$ stretching region have been shown to disappear with hydrous - anhydrous transformation, with the appearance of sharp absorption bands around $3600 \mathrm{~cm}^{-1} .38$

ZC-Ac prepared in this work is layered and possesses high range ordering in the $c$ direction as shown in the lower panel of Figure $\underline{3} A$; the PXRD profile show intense $00 I(I=1$ to 3$)$ Bragg reflections which are equally spaced. The interlayer distance of $9.43 \pm 0.03 \AA$ obtained for ZC-Ac is comparable to literature values ( $9.3 \AA$ and $9.46 \AA$ ) reported for material prepared using the same method. $\stackrel{21,32}{ }$ The formula for ZC-Ac $\left(\mathrm{ZnCu}_{2.8}(\mathrm{OH})_{5.3}(\mathrm{Ac})_{1.7} \cdot 2.6 \mathrm{H}_{2} \mathrm{O}\right)$, obtained from elemental analysis data (Table $\underline{\mathrm{S} 1}$ ) and TGA results (Figure $\underline{\mathrm{S} 3}$ ), presented in Supporting Information, indicate that ZC-Ac has a significant amount of intercalated water molecules. When the acetate group in ZC-Ac was replaced with $\mathrm{Cn}$ ion, a shift of the Bragg reflections to lower $2 \theta$ values was observed indicating expansion of the interlayer space, the interlayer distance increased to $20.21 \pm 0.09$ $\AA$. The increase in the basal spacing is consistent with a smaller ion (acetate ion chain length $=2.53 \AA$ ) being replaced by a larger anion ( $\mathrm{Cn}$ chain length $=8.62 \AA$ ) and with the cinnamate anions adopting a close to bilayer orientation. 
NOT THE PUBLISHED VERSION; this is the author's final, peer-reviewed manuscript. The published version may be accessed by following the link in the citation at the bottom of the page.
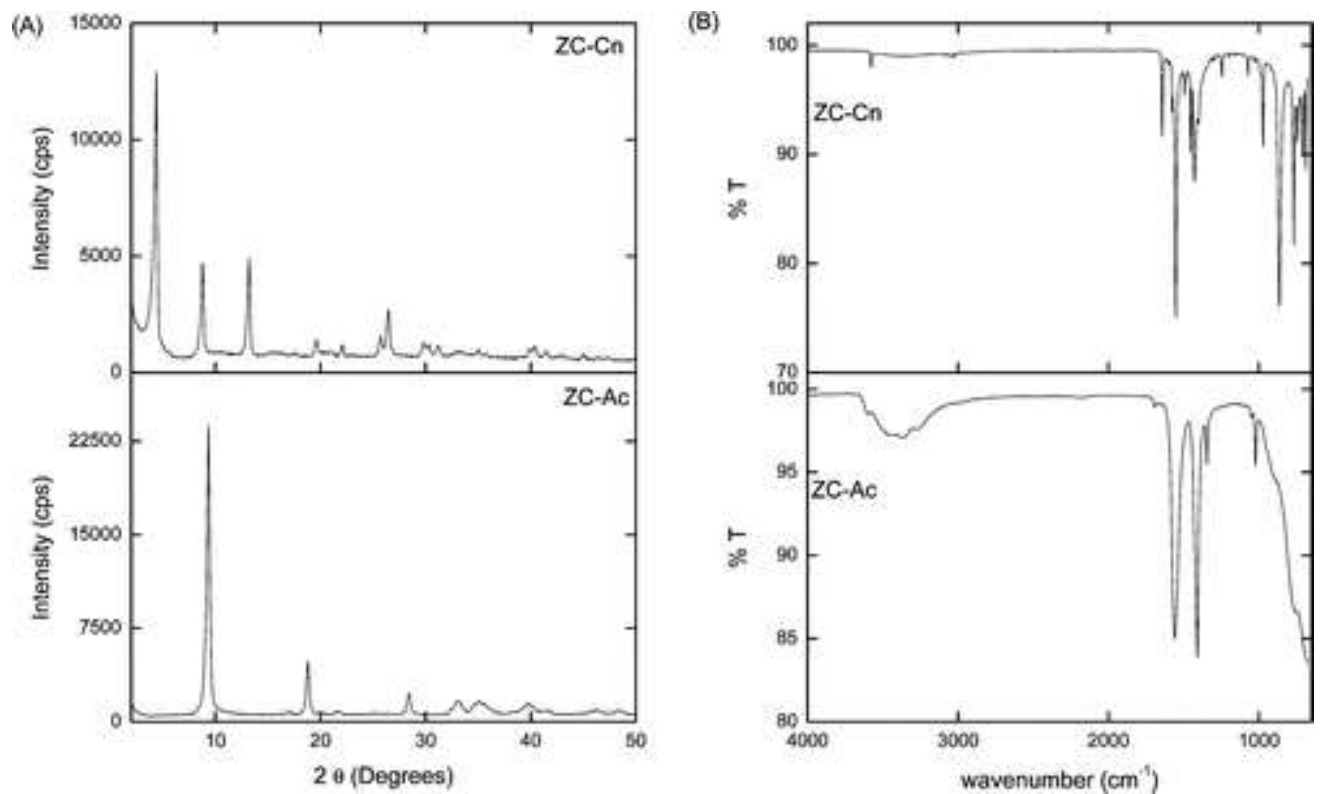

Figure 3. (A) PXRD profiles for ZC-Ac and ZC-Cn. (B) FTIR spectra for ZC-Ac and ZC$\mathrm{Cn}$.

IR spectra presented in Figure $3 \mathrm{~B}$ shows that peaks due to $\mathrm{C}=\mathrm{O}$ vibrations of acetate ion in ZC-Ac (Uasym $=1563 \mathrm{~cm}^{-1}$ and $U_{\text {sym }}=1410$ $\mathrm{cm}^{-1}$ ) were replaced by a series of peaks due to $\mathrm{Cn}$ vibrations (1642 $\mathrm{cm}^{-1}, \mathrm{C}=\mathrm{C}$ bond vibration of the $\mathrm{a}, \beta$-unsaturated carboxylate group; $1551 \mathrm{~cm}^{-1}, \mathrm{U}_{\text {asym }} \mathrm{C}=\mathrm{O}$ and $1428 \mathrm{~cm}^{-1}, \mathrm{U}_{\text {sym }} \mathrm{C}=0$ )-indicating complete replacement of acetate ions with $\mathrm{Cn}$ ions. $\mathrm{ZC}$-Ac has a broad peak centered around $3400 \mathrm{~cm}^{-1}$ which is due to $\mathrm{O}-\mathrm{H}$ stretch of hydrogen bonded water and/or layer hydroxyl groups. Upon exchanging acetate with $\mathrm{Cn}$, the broad hydroxyl band in ZC-Ac was replaced by a single sharp peak at $3577 \mathrm{~cm}^{-1}$ in ZC-Cn; this is consistent with losing water of intercalation as the acetate ion was replaced by $\mathrm{Cn}$ resulting resulting in the layer hydroxyl groups being free, $\underline{38}$ consistent with elemental analysis data, Table $\underline{\mathrm{S} 1}$, and TGA data, Figure $\underline{\mathrm{S} 2}$, provided in Supporting Information.

\subsection{Kinetic Analysis}

Anionic exchange reactions in clays are generally viewed as topotactic, with overall structural integrity maintained during the reaction, although the nature of the lamellar structure and the anions involved can result in a dissolution-reprecipitation mechanism. $\frac{39}{\text { The }}$ reactions may involve multiple steps which include:

Journal of Physical Chemistry A, Vol 114, No. 49 (December 16, 2010): pg. 12858-12869. DOI. This article is (C) American Chemical Society and permission has been granted for this version to appear in e-Publications@Marquette. American Chemical Society does not grant permission for this article to be further copied/distributed or hosted elsewhere without the express permission from American Chemical Society. 
- Transport of the guest ions in the bulk solution and their subsequent diffusion across the liquid film surrounding the lamellar compound;

- Diffusion of the guest within the interlayer space to completely fill the space;

- Chemical reaction at exchange sites within the layers;

- Diffusion of the host anion (displaced from the layers) in the interlayer space and its subsequent diffusion in the bulk solution away from the lamellar compound.

\subsection{Kinetic Analysis in C-o-HCn}

The PXRD analysis of the solid samples obtained during the exchange reaction provides insight into the transformation of both the guest phase and the host phase during the reaction. Selections of traces at different time periods for all the temperatures are shown in Figure 4 . In addition to reflections from $\mathrm{o}-\mathrm{HCn}$, new reflections that increase in intensity with time appear at higher $2 \theta$ values. These reflections are assigned to layered products containing intercalated $\mathrm{Cl}^{-}$ ions. There are two $\mathrm{Cl}^{-}$phases, with the one with higher intensity (major phase) being indexed as monoclinic botallackite $\left\{\mathrm{Cu}_{2}(\mathrm{OH})_{3} \mathrm{Cl}\right\}$, space group $P 2_{1} / m$ (11), PDF \# 58-520, and the minor phase (lower intensity) was indexed as monoclinic clinoatacamite $\left\{\mathrm{Cu}_{2} \mathrm{Cl}(\mathrm{OH})_{3}\right\}$, space group $P 21 / n$ (14), PDF \# 50-1559. $\frac{34}{4}$ The botallackite phase has a 001 peak at $2 \theta=15.5^{\circ}$ corresponding to a $d$-spacing of $5.74 \pm$ $0.049 \AA$ which is in close agreement with reported value for $\mathrm{Cu}_{2}(\mathrm{OH})_{3} \mathrm{Cl}$ of $5.726 \AA . \underline{40}$ The clinoatacamite phase 011 peak at $16.2^{\circ}$, corresponding to a $d$-spacing of $5.29 \pm 0.03 \AA$, is in agreement with reported value of $5.47 \AA . \underline{41}$ The assignments have been confirmed by examining higher angle data as shown in Figure $\underline{S 4}$ in Supporting Information. In Figure $\underline{4}$, the $0-\mathrm{HCn}$ phase is marked by closed diamonds, botallackite phase by closed circles and the clinoatacamite phase by closed squares. As expected for release kinetics, the intensity of the $\mathrm{Cl}^{-}$phases (guest anion) increase with time while the $\mathrm{o}-\mathrm{HCn}$ phase intensity (host anion) decrease relative to the $\mathrm{Cl}^{-}$phase. The reaction does not go to completion since the Bragg reflections from the $o-\mathrm{HCn}$ phase are still observed at equilibrium $\left(t_{\infty}\right)$. 


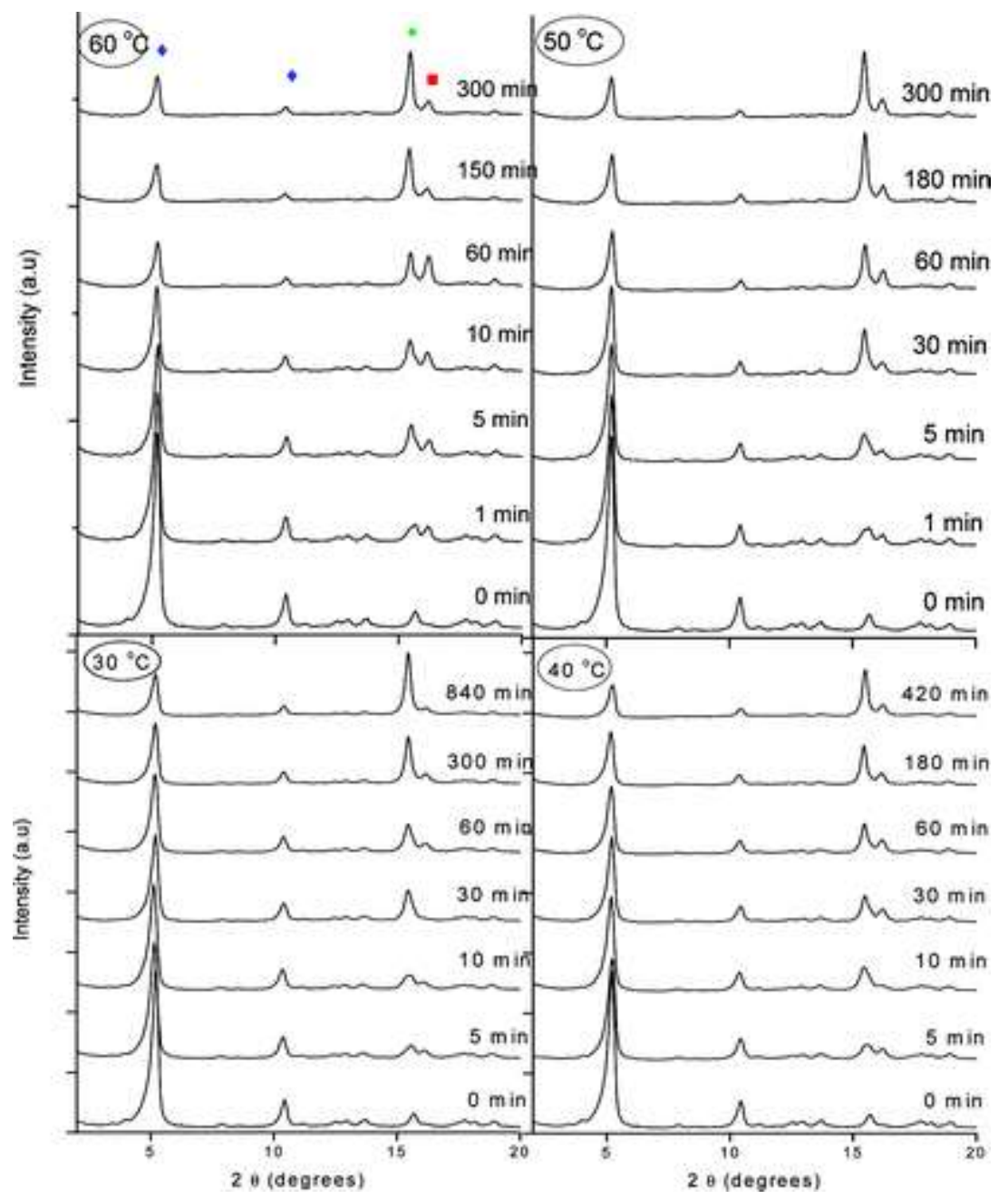

Figure 4. PXRD profile for solid samples collected at different times and at different temperatures for the $\mathrm{C}-\mathrm{o}-\mathrm{HCn} / \mathrm{Cl}^{-}$reaction. The $\mathrm{o}-\mathrm{HCn}$ phase is represented by closed diamonds, botallackite phase by closed circles and the clinoatacamite phase by closed squares.

The intercalation mechanism in layered materials has been shown to involve staging in materials with flexible layers such as graphite intercalation compounds (GIC), this phenomenon of staging involves filling of every $n^{\text {th }}$ layer in the $n^{\text {th }}$ stage compound. $\frac{42}{\text { Staging }}$ has been postulated to be a mechanism for lowering of the activation energy for intercalation and exchange reactions. 43 Although the layers in clays are too rigid for staging to occur, $\underline{44,45}$ the phenomenon has, however, been observed in a few LDH systems where only second stage compounds have been formed; in LDHs staging depends on the intercalated anions and the composition of the layers. $43,46-49$ Secondstage compounds contain alternating interlayers occupied by different 
anions. Only first-order staging was observed in this study since the XRD profiles did not show series of $00 /$ basal reflections at $2 \theta$ positions corresponding to the sum of the interlayer space of the starting material and the fully exchanged product (for second order stage compound) as shown in Figure $\underline{4}$. The absence of higher order staging may indicate that the interaction between the layers and the initial anion are strong as compared to the layer-guest interaction resulting in a small reduction in the $E_{a}$ being attained through staging. $\underline{49}$

The extent of reaction as a function of time plots obtained from solid state transformations at different temperatures are shown in Figure $\underline{5} \mathrm{~A}$. The sum of peak heights of the 001 botallackite and the 011 clinoatacamite reflections was used to determine the product $I_{g(t)}$ values. The extent of reaction versus time data were fit to the Avrami -Erofe'ev nucleation-growth model (eq 1 ); the model provided good fit within the range of a of $0.15-0.85$ as has been observed for other intercalation reactions in layered materials. $\frac{21,50}{}$ Within this specified range of $a$, the model fits the obtained experimental data as shown from the corresponding double-logarithmic plots in Figure $\underline{5} B$, where straight lines were obtained with $\mathrm{R}^{2}$ values ranging from 0.986 to 0.996 . The double-logarithmic plots shown in Figure $\underline{5} B$ are almost parallel with an $n$ value of $\sim 0.5$ indicating that, for the temperature range used here, the mechanism is the same and is consistent with being diffusion controlled. $\underline{15}$ UV-vis spectroscopy was used to determine the accumulated amounts of $\mathrm{O}-\mathrm{HCn}$ in the filtrate, and hence the amount of host anion released into solution. Since the Avrami-Erofe'ev model has been successfully applied to liquid phase UV-Vis and NMR data of released anions, $\underline{7,21,51}$ it was also applied here to the solution data in order to determine whether the model provides a good description of the release process. The release profiles are shown in Figure $\underline{6}$ and the corresponding double-logarithmic plots are presented in Supporting Information Figure S5. The double-logarithmic plots are linear for all the temperatures used here which is an indication that the Avrami-Erofe'ev model provides a good description of the liquid phase data within the range $0.15<a<0.85$. The resulting fits are represented by solid lines in the profiles shown in Figure $\underline{6}$. Similar to the solid phase transformation results, the $n$ values are again consistent with a diffusion controlled process. 
Calculated rate constants $(k)$ and Avrami $n$ coefficients are provided in Table 1 for the kinetics of solid state transformation and the anion release into solution.
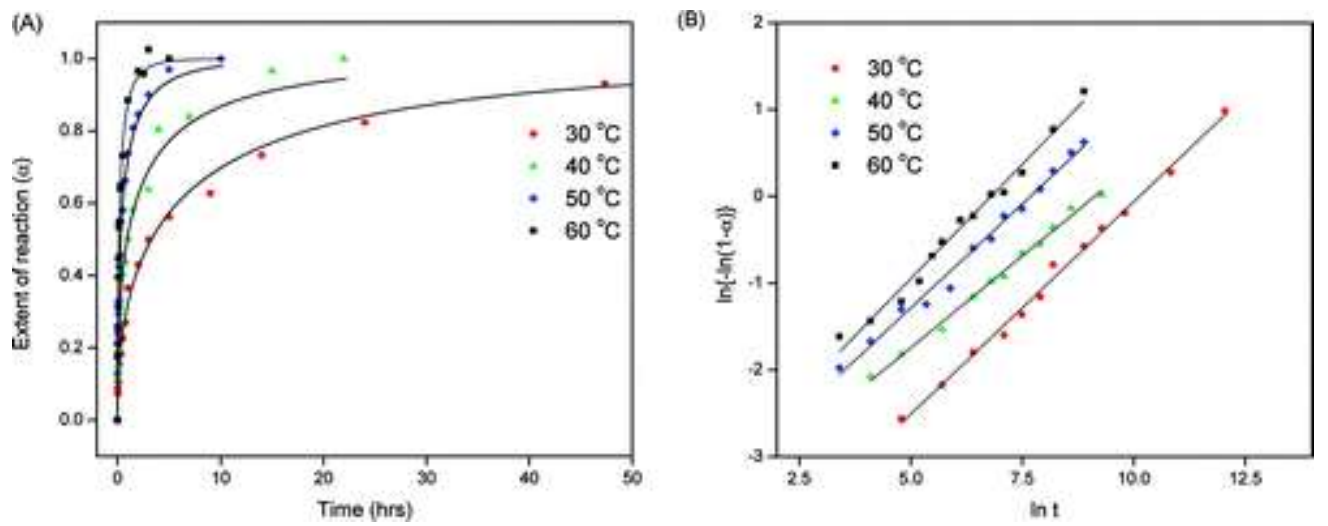

Figure 5. (A) Extent of reaction as a function of time and (B) corresponding doublelogarithmic plots for the exchange reaction of $\mathrm{Cl}^{-}$anion and $\mathrm{C}-\mathrm{O}-\mathrm{HCn}$ at various temperatures for solid state analysis: $60^{\circ} \mathrm{C}(\square), 50^{\circ} \mathrm{C}(\boldsymbol{\bullet}), 40^{\circ} \mathrm{C}(\mathbf{\Delta}), 30^{\circ} \mathrm{C}(\bullet)$, the extent of reaction data has been fitted to Avrami-Erofe'ev equation (solid lines).

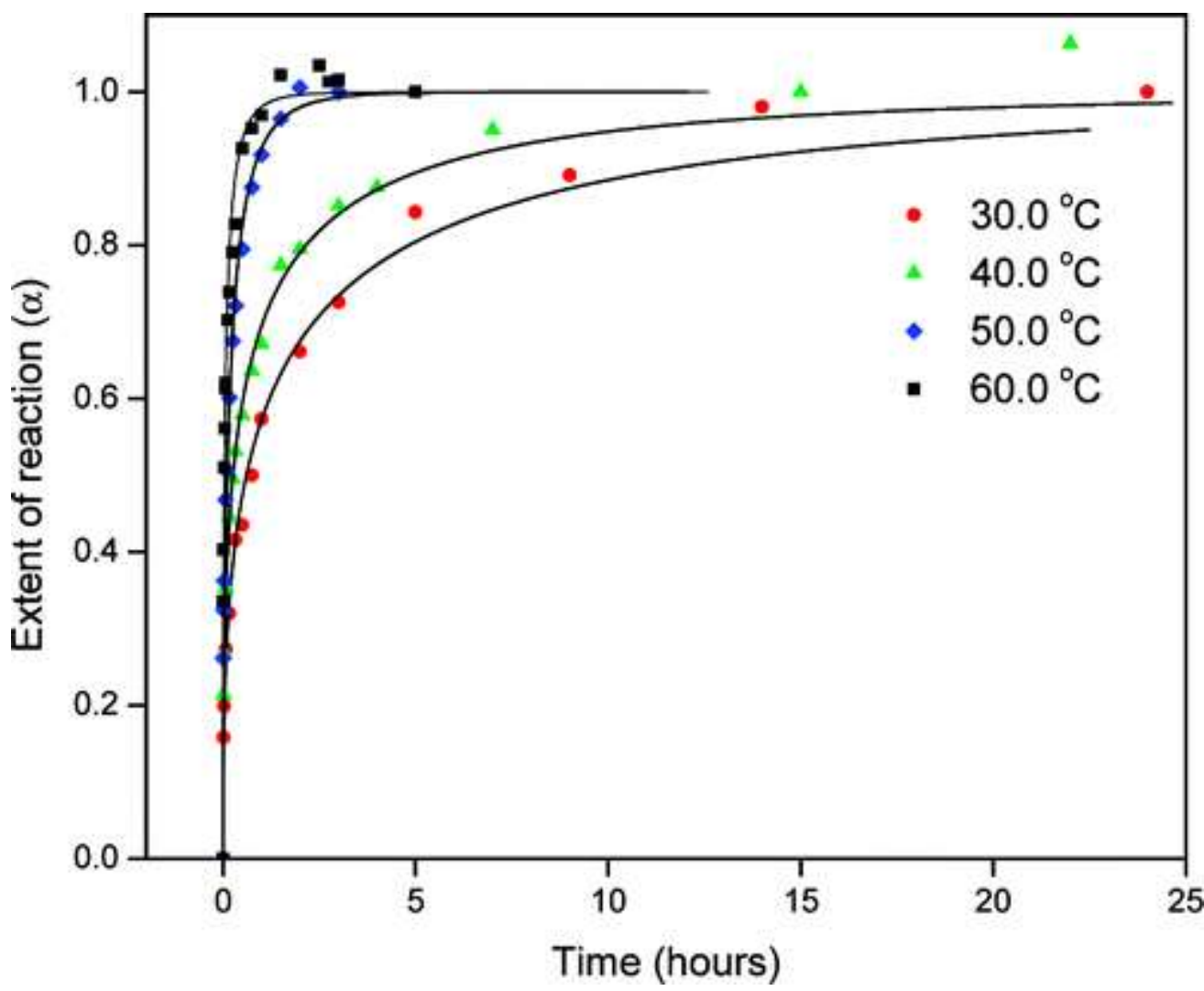

Figure 6. Extent of reaction as a function of time for the exchange reaction of C-o$\mathrm{HCn}$ at various temperatures for solution analysis: $60^{\circ} \mathrm{C}(\square), 50^{\circ} \mathrm{C}(\boldsymbol{1}), 40^{\circ} \mathrm{C}(\boldsymbol{\Delta})$, $30^{\circ} \mathrm{C}(\bullet)$, the extent of reaction data has been fitted to Avrami-Erofe'ev equation.

Journal of Physical Chemistry A, Vol 114, No. 49 (December 16, 2010): pg. 12858-12869. DOI. This article is (C) American Chemical Society and permission has been granted for this version to appear in e-Publications@Marquette. American Chemical Society does not grant permission for this article to be further copied/distributed or hosted elsewhere without the express permission from American Chemical Society. 
NOT THE PUBLISHED VERSION; this is the author's final, peer-reviewed manuscript. The published version may be accessed by following the link in the citation at the bottom of the page.

Table 1. Summary of Solid State and Solution Analysis Kinetic Parameters Obtained from the Double-Logarithmic Plots Analysis for the Reaction of C-O$\mathrm{HCn}$ at Different Temperatures

Solid state

\begin{tabular}{lll}
$\boldsymbol{T}\left({ }^{\circ} \mathbf{C}\right)$ & \multicolumn{1}{c}{$\boldsymbol{n}$} & \multicolumn{1}{c}{$\mathbf{k ~ s}^{-\mathbf{1}}\left(\times \mathbf{1 0}^{-4}\right)$} \\
60.0 & $0.52 \pm 0.02$ & $11 \pm 3$ \\
50.0 & $0.48 \pm 0.01$ & $4 \pm 1$ \\
40.0 & $0.45 \pm 0.01$ & $1.3 \pm 0.2$ \\
30.0 & $0.45 \pm 0.01$ & $0.4 \pm 0.1$
\end{tabular}

Solution phase

$\begin{array}{ll}0.397 \pm 0.006 & 29 \pm 4 \\ 0.45 \pm 0.02 & 16 \pm 4 \\ 0.39 \pm 0.06 & 4.3 \pm 0.7 \\ 0.40 \pm 0.01 & 1.6 \pm 0.4\end{array}$

As observed in Table 1 , the rate constants obtained for anion release into solution are three to four times larger than the corresponding rate constants for the solid state transformation. The differences between solution analysis and solid state transformation may indicate that the loss of the host anion and subsequent loss of coherent diffraction from the host phase occurs faster than the gain in coherent diffraction from the product phase. This has been observed in other systems and maybe due to the presence of an intermediate with poor crystallinity $\underline{52}$ or a delayed appearance of the guest phase which may be because a significant number of layers need to be filled with the guest to observe Bragg reflection from the guest phase. Since higher order staging was not observed in this study, the onset of the exchange reaction may then occur from the outermost layers, and parallel to the layers as observed in the intercalation of $\mathrm{NH}_{3}$ into $\mathrm{TaS}_{2} \underline{53}$ and deintercalation of mercury from TiS $2 . \underline{54}$ Johnsen et al. $\frac{55}{5}$ observed a similar effect in the exchange reaction of chloride into carbonatecontaining LDH. In cases such as these, mixed phases with different interlayer separations should be observed in XRD profiles. $\underline{56}$ The progressive increase in the number of layers occupied by the guest anions results in the growth of the guest phase and the decay of the host phase with time as observed in XRD profiles.

In our system, if the anion exchange reaction proceeds from layer-to-layer, with a smaller anion replacing a larger anion, then the rigid HDS layers are expected to collapse to the interlayer dimension of the guest phase when the majority of the host anions in the layers have been replaced. Unless the complete exchange within the individual layers is instantaneous, the growth of the guest phase and the decay of the host phase may be delayed relative to the time that host anions are observed being released into solution. Therefore, some of the C-O-HCn may be consumed and significant amount of $\mathrm{O}-\mathrm{HCn}$ 
released into solution without subsequent appearance of guest diffraction peaks. $\frac{49,57,58}{}$ Due to the ex situ analysis of the solid product, the decay of the host phase was referenced to the growth of the guest (chloride) phase in obtaining the extent of reaction as shown in eq $\underline{6}$. The rate of decay of the host phase and the growth of the guest phase are therefore interlinked to give the observed rate constants. The low rate of growth of the chloride phase due to factors indicated above will affect the extent of reaction values obtained, resulting in the observed lower rates of reaction compared to solution analysis.

The temperature dependence of the reaction was evaluated via Arrhenius plots shown in Supporting Information Figure $\underline{\mathbf{6} 6}$. The value of the effective activation energy was $91 \pm 3 \mathrm{~kJ} / \mathrm{mol}$ for the solid phase transformation (Figure S6A of the Supporting Information). The Arrhenius plot for the anion release into solution, Figure $\underline{\mathrm{S} 6 \mathrm{~B}}$ of the Supporting Information, resulted in an $E_{\mathrm{a}}$ of $84 \pm 5 \mathrm{~kJ} / \mathrm{mol}$. These values are not significantly different indicating that the temperature dependence obtained from these two approaches is comparable. When the chemical reaction at the exchange sites is rapid, the transport process (by diffusion) then determines the overall rate of reaction. The Avrami $n$ coefficient values obtained from analyzing both the solid materials and the solution phase released anion concentrations were, as noted previously, consistent with a diffusion-controlled mechanism. Diffusion-controlled processes have been shown to have varying $E_{a}$ values depending on the nature of the reaction conditions. While the value for aqueous diffusion-controlled reactions of ions is low ( $\sim 15 \mathrm{~kJ}$ $\left.\mathrm{mol}^{-1}\right), \underline{59}$ values for surface adsorption processes are reported to be as high as $30 \mathrm{~kJ} \mathrm{~mol}^{-1}$. 60 During the sorption of 2,4Dichlorophenoxyacetate on various clays, Haque et al. $\underline{61}$ observed $E_{a}$ values ranging from $12-21 \mathrm{~kJ} \mathrm{~mol}^{-1}$. Lv et al. $\underline{62}$ obtained two $E_{\mathrm{a}}$ values for the two-step removal of fluoride ions from solution using an LDH. The fast first step was considered to be diffusion controlled and had an $E_{\mathrm{a}}$ value of $37 \mathrm{kJmol}^{-1}$, while the second slower step, with an $E_{\mathrm{a}}$ value of $72 \mathrm{~kJ} \mathrm{~mol}^{-1}$, was proposed to be controlled by the chemical reaction of $\mathrm{F}^{-}$with the LDH layers. $\underline{62}$ The $E_{\mathrm{a}}$ values for 2-dimensional (2-D) diffusion within the layers may be even higher, depending on the nature of the interlayer species and how densely packed the anions are. When the interlayer species are organic anions, the diffusion through the organic matrix can resemble diffusion through polymers 
with $E_{\mathrm{a}}$ values ranging up to $100 \mathrm{~kJ} \mathrm{~mol}^{-1}$, depending on the diffusing molecule. $\frac{63}{}$ In ion exchange reactions in lamellar compounds, Ragavan et al. $\underline{50}$ found an activation energy of $43 \mathrm{~kJ} \mathrm{~mol}^{-1}$ for the diffusioncontrolled intercalation of 4-chlorophenoxyacetate and $53-62 \mathrm{~kJ} \mathrm{~mol}^{-1}$ for intercalation reactions presumed to be controlled by nucleation at the edge of the layers, based on the Avrami model results. The $E_{a}$ values for processes controlled by reactions of the anions with the lamellar compounds have been shown to range from $30-70 \mathrm{~kJ} \mathrm{~mol}^{-1}$ depending on the nature and size of the guest anions, with larger anions having higher $E_{a}$ values. $\underline{50,52,64}$ If our reaction is diffusioncontrolled, as implied by the Avrami $n$ values, then 2-D diffusion in the interlayer region would be the most likely rate determining factor. However, a mechanistic contribution from the exchange reaction cannot be ruled out.

While the Avrami model appears to fit the data with similar values of $\mathrm{n}$ obtained at the range of temperatures used here, it is clear from Figure $\underline{5}$ that fit is not perfect, particularly at higher conversions at $40^{\circ} \mathrm{C}$. Isoconversional analysis offers the advantage of being able to determine the variation of activation energy as a function of reaction progress; this provides information regarding how the reaction mechanism may change as a function of extent of reaction. $\underline{25}$ The results obtained from isoconversional analysis for solid state analysis and solution analysis are shown in Figure $\underline{7}$, parts $A$ and $B$, respectively. The $E_{\mathrm{a}}$ values obtained for solid state data range from 87-96 kJ mol-1 and those for solution analysis range from 78-85 kJ $\mathrm{mol}^{-1}$. The data shown in Figure $\underline{7}$ for both solid state and solution analysis reveal that, within experimental error, the $E_{a}$ does not significantly change as a function of extent of reaction. This is an indication that the reaction can be described as proceeding via a single mechanism, consistent with fact that the Avrami $n$ values did not vary significantly as a function of temperature for each data set. The $E_{a}$ values obtained from the Avrami-Erofe'ev analysis lie within the range of values obtained using isoconversional method, indicating that in this case the model fitting approach provides reliable averaged global effective activation energy for the entire reaction. As noted above, the $E_{a}$ values obtained are too high to be explained by diffusion of ions in solution alone, 2-D diffusion in a densely packed interlayer region may explain the high $E_{a}$ values obtained here. In basic copper nitrate, the 
interlayer anions are grafted onto the layers, $\underline{65}$ consistent with FTIR analysis discussed earlier. The $\mathrm{o}-\mathrm{HCn}$ is therefore also expected to be bound to the layer and the observed $E_{a}$ values are also consistent with a mechanism in which the rate is determined by the reaction at the exchange site. Since $E_{a}$ does not vary as a function of extent of reaction, fitting the data to a single reaction model is appropriate but further work is necessary to better characterize the nature of the ratedetermining process.
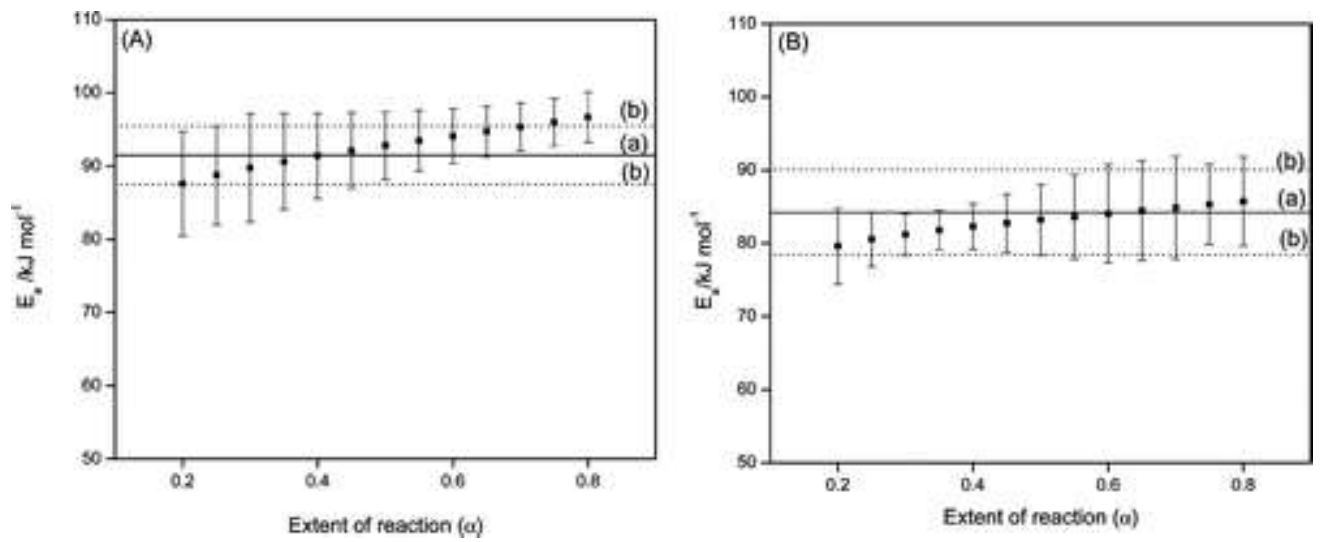

Figure 7. Variation of effective $E_{a}$ with a for (A) solid state analysis and (B) Solution analysis. The solid line (a) represents the Arrhenius determined $E_{a}$ together with the associated errors (broken lines, b).

\subsection{Kinetic Analysis for ZC-Cn}

The solid state transformation of both the guest and the host phases during the replacement of $\mathrm{Cn}$ by chloride in the ZC-Cn HDS host are shown in Figure $\underline{8}$, with the chloride phase indicated by an arrow. There is a small induction period observed at low temperatures (30 and $40{ }^{\circ} \mathrm{C}$ ) as seen in Figure $\underline{8}$. Induction periods have been observed for other anion exchange reactions $\frac{48}{}$ and may be due to restructuring of the host layers which results in a delayed or slow release of the $\mathrm{Cn}$ anions and subsequent delayed crystallization and/or growth of the guest phase. During the induction period, the chloride phase is not observed for a period of up to $5 \mathrm{~min}$ at $30^{\circ} \mathrm{C}$, and then starts to grow slowly with Bragg reflections having very low intensities in samples obtained for reaction times less than $20 \mathrm{~min}$. This effect is also observed in solution analysis where there was linear and slow increase in the concentration of released $\mathrm{Cn}$ in the first $30 \mathrm{~min}$ (Figure $\underline{\mathrm{S7}}$, in Supporting Information). Possibilities for the slow release of $\mathrm{Cn}$ 
ions without corresponding growth of guest phase include (1) that there were $\mathrm{Cn}$ anions present on the edges of interlayer region of the material, or (2) that there where protonated $\mathrm{Cn}$ molecules adsorbed on the surface. Only trace amounts of $\mathrm{Cn}$ were released when the material was placed in DI water at $40{ }^{\circ} \mathrm{C}$ for $24 \mathrm{~h}$ without any sodium chloride present, much less than the amount released during the induction period. This suggests that the anions released during the induction period were ions on the edges of the lamellar compounds which were exchanged by chloride ions in solution. The chloride phase, which has been indexed as paratacamite, zincian (PDF \# 50-1558), $\underline{34}$ has a first peak (101) at $2 \theta=16.15^{\circ}$ corresponding to a $d$-spacing of $5.47 \pm 0.01$ which is in agreement with the literature value of $5.45 \AA . \underline{66}$ More detail concerning the phase assignment is found in Supporting

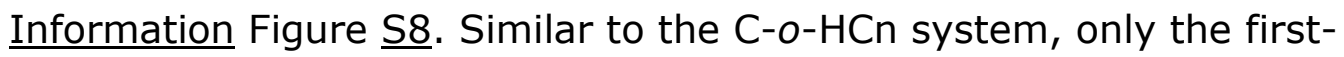
stage compound was observed. 
NOT THE PUBLISHED VERSION; this is the author's final, peer-reviewed manuscript. The published version may be accessed by following the link in the citation at the bottom of the page.

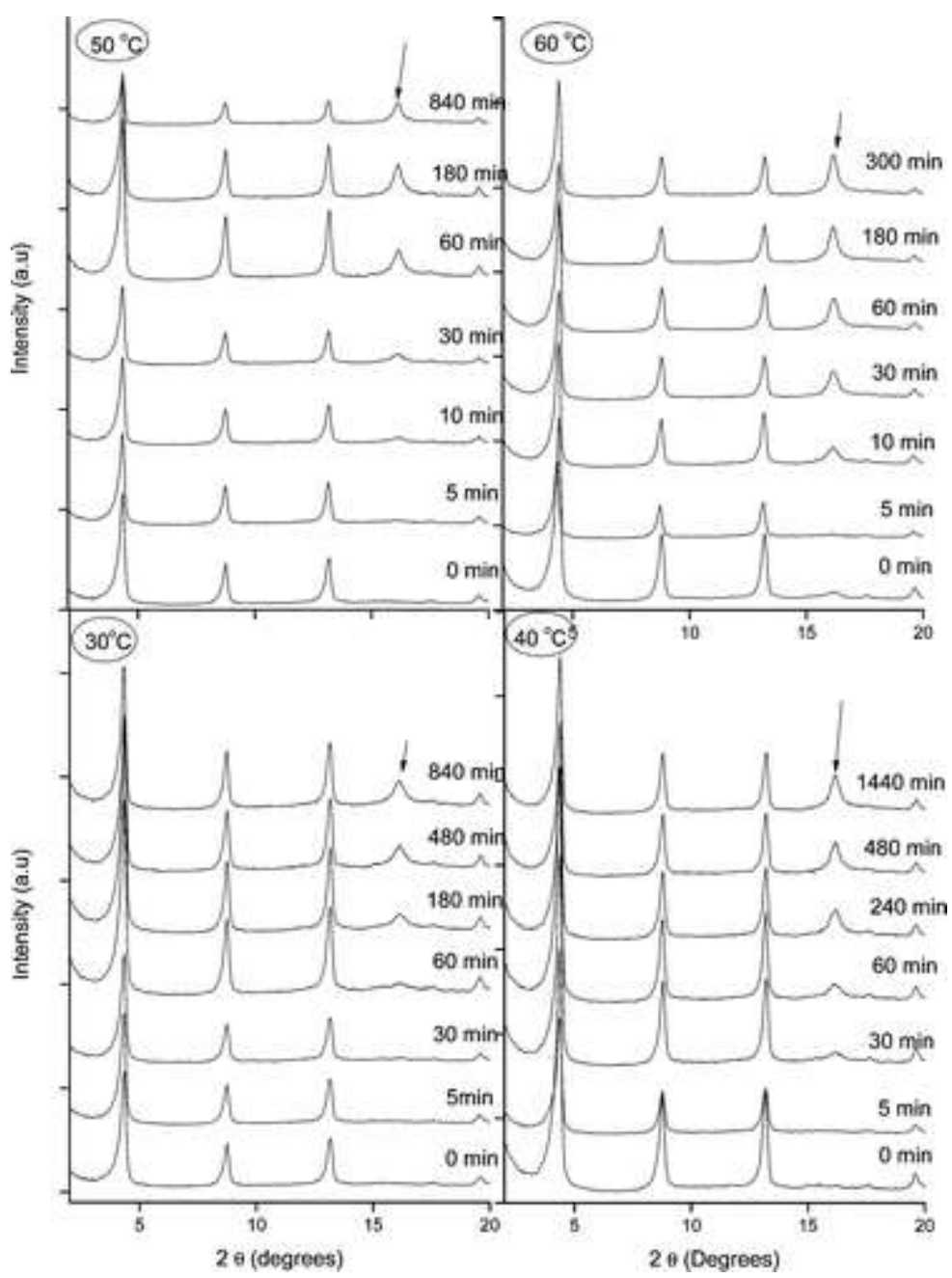

Figure 8. PXRD profile for solid samples collected at different times and different temperatures for the reaction of $\mathrm{ZC}-\mathrm{Cn}$ with chloride anion. The chloride phase is indicated with an arrow.

The absolute extent of reaction for the exchange is low as indicated by the high intensity of the $\mathrm{Cn}$ phase in relation to the guest phase (chloride) at equilibrium. For anion exchange reactions, there are a number of factors which affect the affinity of the HDS layers for guest anion; these include layer-host anion interactions, layer-guest anion interactions, host anion-guest anion interactions within the interlayer space, and the solvation energies of both the host and guest anions. These factors could have resulted in a low equilibrium constant for the exchange reaction.

The extent of reaction versus time plot for solid state transformations at different temperatures are shown in Figure $\underline{9}$, the

Journal of Physical Chemistry A, Vol 114, No. 49 (December 16, 2010): pg. 12858-12869. DOI. This article is (C) American Chemical Society and permission has been granted for this version to appear in e-Publications@Marquette. American Chemical Society does not grant permission for this article to be further copied/distributed or hosted elsewhere without the express permission from American Chemical Society. 
data were again fit to the Avrami-Erofe'ev nucleation-growth model (solid line) using double-logarithmic plots (found in Supporting

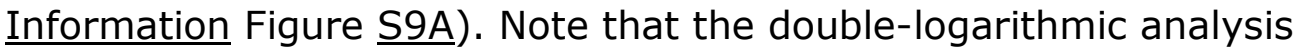
required an offset in the lower temperature for $t_{0}$ in order to take into account the induction period. While linear double-logarithmic plots were obtained, the Avrami-Erofe'ev model does not extrapolate to fit the induction region $\mathrm{a}<0.15$ for the lower temperatures, as is evident in the insert in Figure $\underline{9}$. The Avrami exponent obtained in this analysis ranged from 0.6 to 0.9 , indicating that for the temperatures 30 and $40^{\circ} \mathrm{C}(n \approx 0.6)$ the reaction appears primarily diffusion controlled and for 50 and $60^{\circ} \mathrm{C}(n \approx 0.9)$ there may be contributions from both diffusion and nucleation. $\underline{\underline{21}}$ The rate constants obtained for both the solid state transformation and the solution analysis are not significantly different which may indicate that the solid state transformation has the same general kinetics as the release of anions into solution for $0.15<a<1.0$. In this case, due to the induction period and the corresponding low initial release of $\mathrm{Cn}$ anions into solution, the loss of the host anions and subsequent loss of coherent diffraction from the host phase occurred at the same rate as the gain in coherent diffraction from the product phase. 


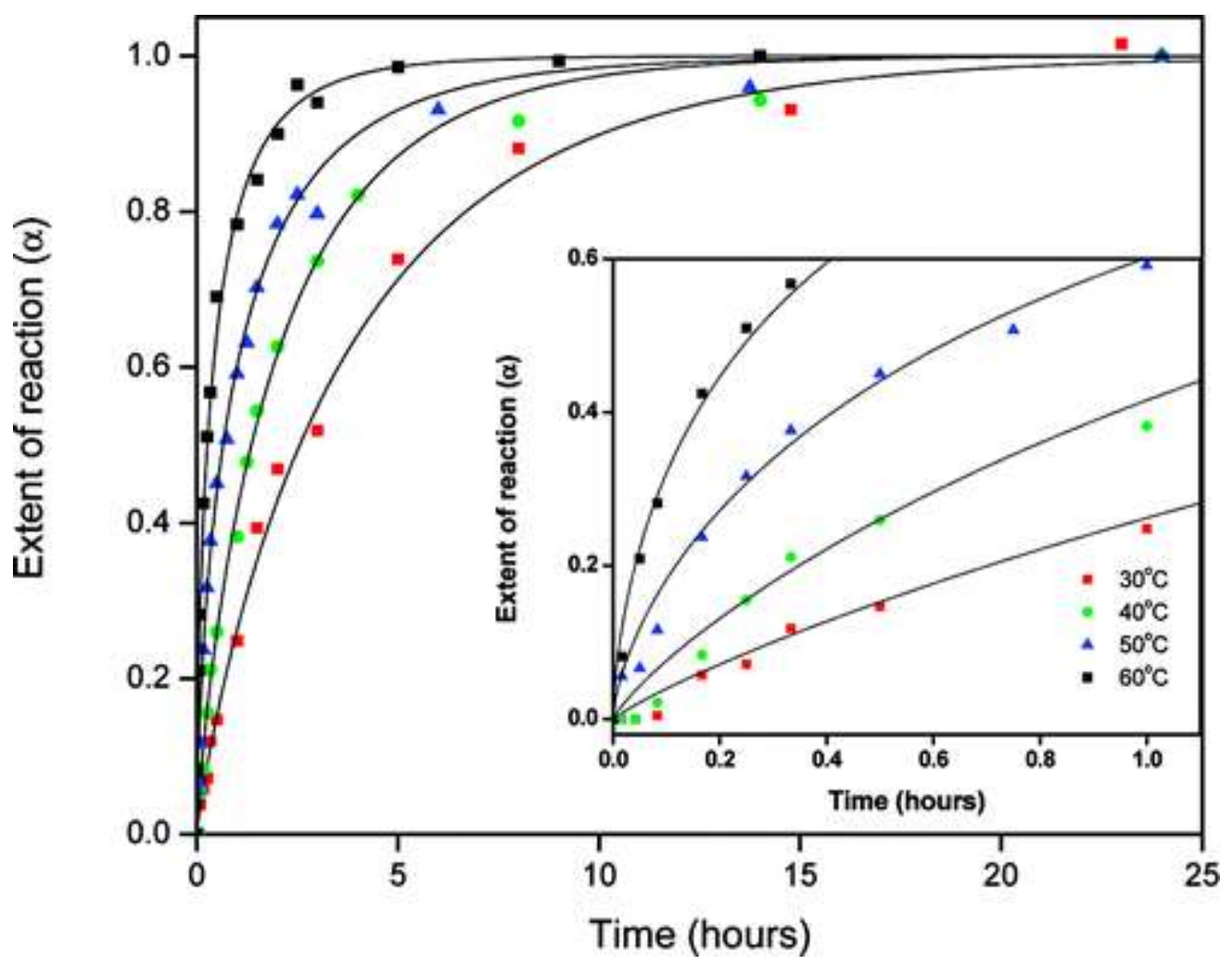

Figure 9. Release profile for the exchange reaction of $\mathrm{Cl}^{-}$and $\mathrm{ZC}-\mathrm{Cn}$ at various temperatures for solid state analysis: $60^{\circ} \mathrm{C}(\square), 50{ }^{\circ} \mathrm{C}$ (blue $\boldsymbol{\Delta}$ ), $40^{\circ} \mathrm{C}$ (green $\bullet$ ), $30{ }^{\circ} \mathrm{C}$ (red $\square$ ). The insert shows low time regime highlighting the induction period for 30 and $40^{\circ} \mathrm{C}$, note the induction is no longer present at higher temperatures.

The Avrami-Erofe'ev model was also applied to the solution data obtained from UV-vis spectroscopy. The release profiles are shown in Figure 10 (corresponding double-logarithmic plots are in Supporting Information Figure $\mathrm{S9B}$ ). The Avrami exponents obtained ranged from 0.4 to 0.8 ; with a similar temperature dependent variation as observed in the solid phase data. The kinetic parameters obtained from doublelogarithmic analysis are presented in Table $\underline{2}$. The effective activation energy for the release of $\mathrm{Cn}$ was obtained by using both model fitting methods and model free methods. The Arrhenius plots for the Avrami model data are shown in Figure $\underline{\mathrm{S} 6 \mathrm{C}}$ for solid state analysis and Figure S6D of the Supporting Information for solution analysis. For solid state transformation, the Avrami model led to activation energy of $58 \pm 4$ $\mathrm{kJ} / \mathrm{mol}$. The corresponding $E_{\mathrm{a}}$ for monitoring the anion release into solution was $45 \pm 7 \mathrm{~kJ} / \mathrm{mol}$. These values obtained from both solid state and solution analysis are comparable; this is to be expected since the rate constants are not significantly different therefore the temperature dependence is not expected to be different. 


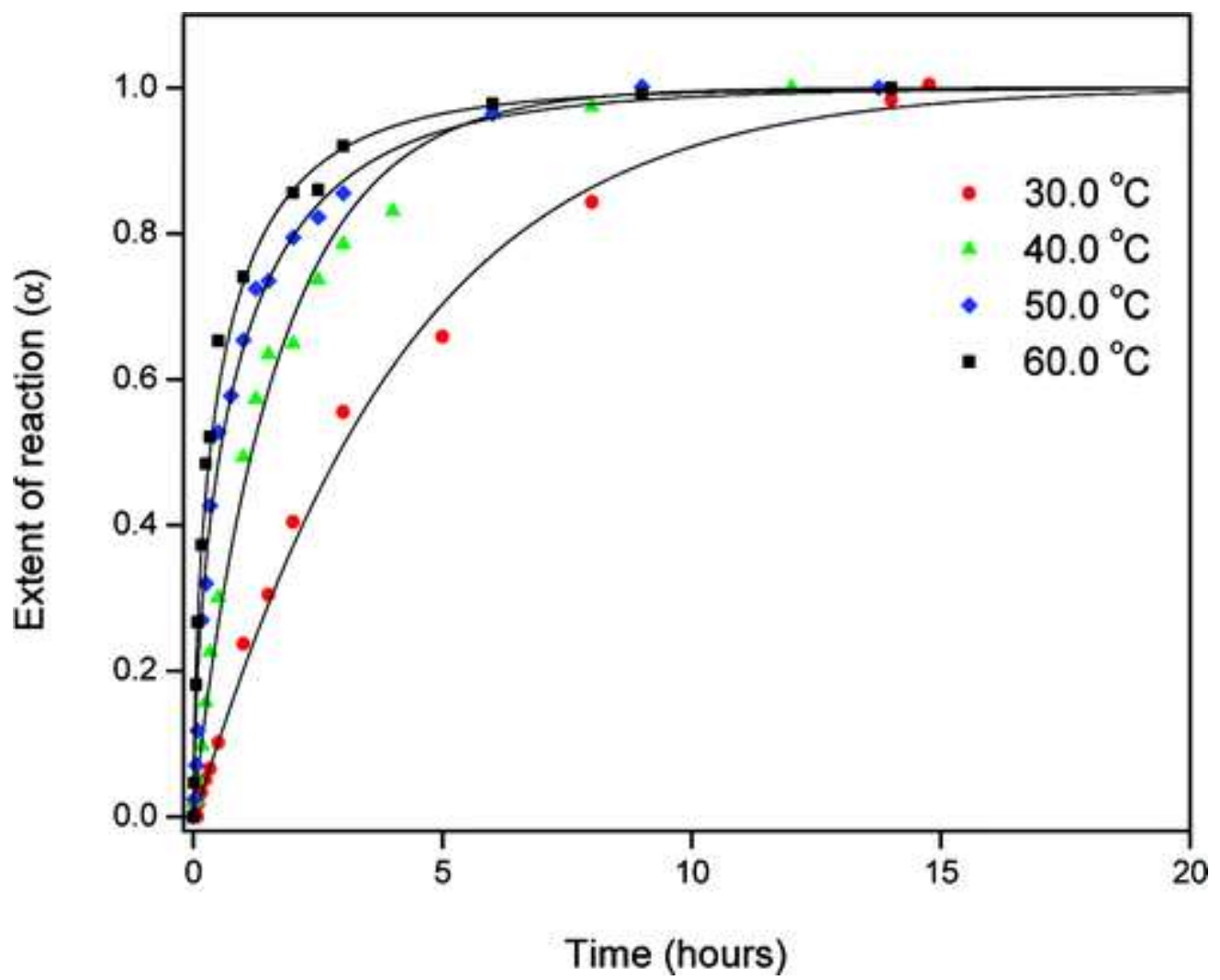

Figure 10. Extent of reaction as a function of time for the exchange reaction of $\mathrm{Cl}^{-}$ anion and ZC-Cn at various temperatures for solution analysis: $60^{\circ} \mathrm{C}(\square), 50^{\circ} \mathrm{C}(1)$, $40{ }^{\circ} \mathrm{C}(\boldsymbol{\nabla}), 30^{\circ} \mathrm{C}(\bullet)$, data has been fitted to Avrami -Erofe'ev equation.

Table 2. Summary of Kinetic Parameters Obtained at Different Temperatures for the Reaction of ZC-Cn with $\mathrm{Cl}^{-}$

\section{Solid state}

\begin{tabular}{lclll}
$\boldsymbol{T}\left({ }^{\circ} \mathbf{C}\right)$ & \multicolumn{1}{c}{$\boldsymbol{n}$} & \multicolumn{1}{c}{$\mathbf{k ~ s}^{-\mathbf{1}}\left(\mathbf{\times 1 \mathbf { 1 0 } ^ { - 4 } )}\right.$} & $\boldsymbol{n}$ & \multicolumn{1}{c}{$\mathbf{k ~ s}^{-\mathbf{1}}\left(\times \mathbf{1 0}^{-\mathbf{4}}\right)$} \\
60.0 & $0.61 \pm 0.02$ & $6 \pm 1$ & $0.41 \pm 0.01$ & $4 \pm 1$ \\
50.0 & $0.66 \pm 0.02$ & $2.4 \pm 0.6$ & $0.60 \pm 0.02$ & $2.9 \pm 0.7$ \\
40.0 & $0.88 \pm 0.01$ & $1.3 \pm 0.4$ & $0.71 \pm 0.02$ & $1.7 \pm 0.4$ \\
30.0 & $0.87 \pm 0.01$ & $0.7 \pm 0.2$ & $0.75 \pm 0.02$ & $0.7 \pm 0.2$
\end{tabular}

The isoconversional treatment of the solid state data shows a linear variation of $E_{a}$ as a function of extent of reaction (Figure $11 \mathrm{~A}$ ). The $E_{\mathrm{a}}$ start at a value of $102 \mathrm{~kJ} \mathrm{~mol}^{-1}$ at an extent of reaction of 0.05 and drops to $45 \mathrm{~kJ} \mathrm{~mol}^{-1}$ at an extent of reaction of 0.8 . There is also variation in the $E_{a}$ with extent of reaction for solution data (Figure $\underline{11 B})$; the $E_{\mathrm{a}}$ does not change significantly from extent of reaction of 0.05 up to $0.15\left(83-80 \mathrm{~kJ} \mathrm{~mol}^{-1}\right)$ and then decreases linearly to $41 \mathrm{~kJ}$ $\mathrm{mol}^{-1}$ at $\mathrm{a}=0.8$. The variation of $E_{\mathrm{a}}$ as a function of extent of reaction 
is an indication that the reaction does not proceed via a single mechanism and the decrease in effective $E_{\mathrm{a}}$ may indicate that there is a decreasing contribution from an initial mechanistic step (or set of steps) with higher $E_{\mathrm{a}}$. The obtained activation energy therefore cannot be assigned to a single process or interpreted in terms of the transition state theory. $\underline{23}$ There is a significant difference between solid state analysis and solution analysis at low extent of reaction $(0.05<a<$ $0.15)$, the $E_{a}$ for solution analysis does not significantly change while the variation in effective activation energy for the solid state reaction is more pronounced. The solution phase analysis showed almost constant $E_{\mathrm{a}}$ at the early stage of reaction where there is release of $\mathrm{Cn}$ from the materials without corresponding growth of the chloride phase. This could be due to chemisorption/desorption of $\mathrm{Cl}^{-}$and $\mathrm{Cn}$ ions on the edges of the interlayer space of the lamellar compound. After the initial chemisorption process at the edges, the exchange of interior (interlayer) $\mathrm{Cn}$ ions could result in increased rates of exchange and increased accumulation of released host anions and subsequent decay and growth of the host and guest anion phases respectively. In the ZC-HCn structure, the layers are positively charged with the charge being generated when a quarter of the octahedral sites in the copper hydroxide layers are vacant and $\mathrm{Zn}^{2+}$ ions occupy the tetrahedral sites on either side of the vacant octahedral site. $\underline{12}$ Therefore, there is electrostatic interaction between the layers and the interlayer anions. It has been observed in anion exchange in LDHs that the exchange and complete replacement of host anions with guest anion within the layers increase the rate of anion-exchange in the neighboring layers. $\underline{55}$ This has also been observed in intercalation reactions in $\mathrm{TiS}_{2}$ where the intercalation of one layer results in the weakening of the neighboring layer reducing the $E_{\mathrm{a}}$ for intercalation. $\underline{67}$ If the reaction rate is controlled by anion exchange within the layers, then lowering of the effective $E_{\mathrm{a}}$ of exchange in the neighboring layers may result in the gradual lowering of $E_{a}$ values for the reaction as the exchange proceeds. This may explain the trend observed in both the solution analysis and solid state analysis. Transition from a chemicalreaction-controlled process to a diffusion-controlled process cannot be ruled out since the $E_{a}$ values obtained at high extent of reaction are in the range of diffusion controlled reactions. However, it is clear in this case that a single mechanism is inadequate to characterize the observed kinetics.

Journal of Physical Chemistry A, Vol 114, No. 49 (December 16, 2010): pg. 12858-12869. DOI. This article is (C) American Chemical Society and permission has been granted for this version to appear in e-Publications@Marquette. American Chemical Society does not grant permission for this article to be further copied/distributed or hosted elsewhere without the express permission from American Chemical Society. 
NOT THE PUBLISHED VERSION; this is the author's final, peer-reviewed manuscript. The published version may be accessed by following the link in the citation at the bottom of the page.
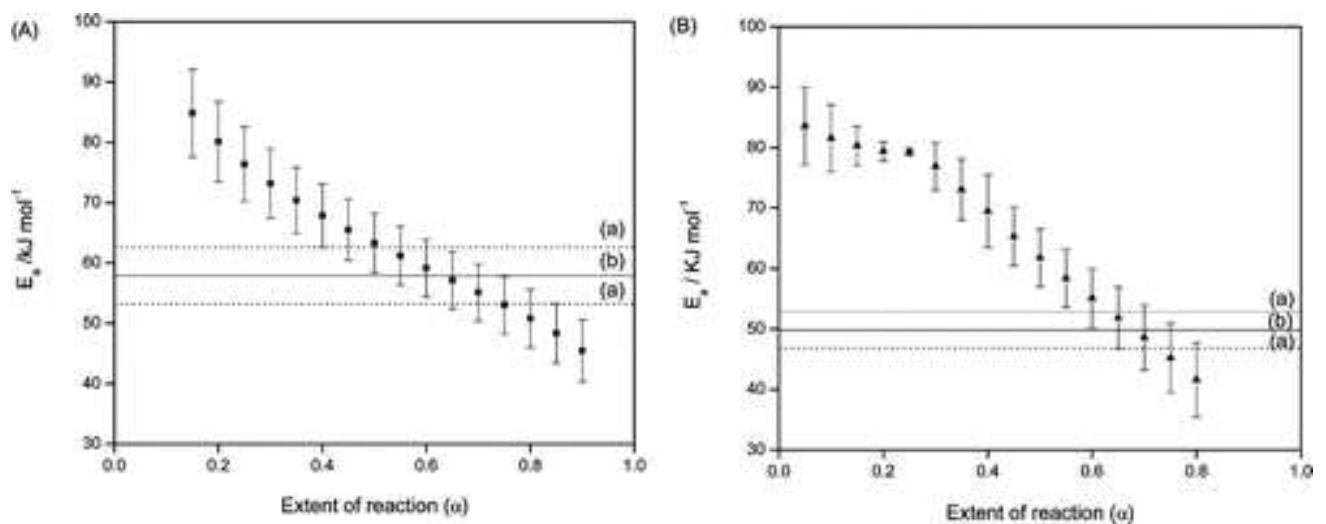

Figure 11. Plot of the variation of activation energy with the extent of reaction (a) for (A) solid state analysis and (B) Solution analysis. The solid line (b) represents the Arrhenius determined activation energy and broken lines (a) represent the associated errors.

Understanding the effect of the metal hydroxide layer structure in potentially controlling the observed kinetics is the subject of ongoing work in our laboratory, using the same host/guest anion combinations with different metal hydroxide layers. In addition, variations in host and/or guest anions in reactions involving the same metal hydroxide layer are also being explored.

\section{Conclusions}

Isoconversional analysis has been successfully applied, for the first time, to anion release kinetics in layered materials. The effective activation energies obtained from isoconversional analysis indicated that, for the $\mathrm{C}-\mathrm{O}-\mathrm{HCn}$ system, there is no variation in the mechanism of the reaction; the $E_{a}$ values remained constant with respect to extent of reaction, within the limits of experimental uncertainty. The effective activation energies for replacement of $\mathrm{O}-\mathrm{HCn}$ by chloride that were extracted from the isoconversional analysis ranged from 87-96 kJ $\mathrm{mol}^{-1}$ in solid state analysis and $78-85 \mathrm{~kJ} \mathrm{~mol}^{-1}$ for solution analysis and were found to be in agreement with those obtained from a global fit to the data using the Avrami-Erofe'ev model. In the second model system presented here, ZC-Cn reaction with chloride, there was a clear variation of the $E_{a}$ with respect to extent of reaction indicating that there where changes in the reaction mechanism as the reaction progressed. The Avrami-Erofe'ev model, or any other single mechanism, is therefore inadequate for modeling the reaction kinetics, particularly for determining the effect of temperature over the entire

Journal of Physical Chemistry A, Vol 114, No. 49 (December 16, 2010): pg. 12858-12869. DOI. This article is (C) American Chemical Society and permission has been granted for this version to appear in e-Publications@Marquette. American Chemical Society does not grant permission for this article to be further copied/distributed or hosted elsewhere without the express permission from American Chemical Society. 
NOT THE PUBLISHED VERSION; this is the author's final, peer-reviewed manuscript. The published version may be accessed by following the link in the citation at the bottom of the page.

extent of reaction. Use of isothermal, isoconversional approaches is a convenient method for testing the applicability of the Avrami (or any other model-based) approach.

\section{Acknowledgment}

This work was supported by the National Science Foundation (CHE-0809751).

\section{References}

${ }^{1}$ Chigwada, G.; Kandare, E.; Wang, D. Y.; Majoni, S.; Mlambo, D.; Wilkie, C. A.; Hossenlopp, J. M. J. Nanosci. Nanotechnol. 2008, 8, 1927- 1936

2Majoni, S.; Su, S.; Hossenlopp, J. M. Polym. Degrad. Stab. 2010, 95, 15931604

${ }^{3}$ Dutta, P. K.; Puri, M. J. Phys. Chem. 1989, 93, 376- 381

${ }^{4}$ Fujita, W.; Awaga, K. Inorg. Chem. 1996, 35, 1915- 1917

${ }^{5}$ Hayashi, H.; Hudson, M. J. J. Mater. Chem. 1995, 5, 781- 783

${ }^{6}$ Taibi, M.; Ammar, S.; Jouini, N.; Fievet, F.; Molinie, P.; Drillon, M. J. Mater. Chem. 2002, 12, 3238- 3244

${ }^{7}$ Khan, A. I.; Ragavan, A.; Fong, B.; Markland, C.; O’Brien, M.; Dunbar, T. G. ; Williams, G. R.; O'Hare, D. Ind. Eng. Chem. Res. 2009, 48, 1019610205

${ }^{8}$ bin Hussein, M. Z.; Zainal, Z.; Yahaya, A. H.; Foo, D. W. V. J. Controlled Release 2002, 82, 417- 427

${ }^{9} \mathrm{Gu}$, Z.; Thomas, A. C.; Xu, Z. P.; Campbell, J. H.; Lu, G. Q. Chem. Mater. 2008, 20, 3715- 3722

${ }^{10}$ Hwang, S. H.; Han, Y. S.; Choy, J. H. Bull. Korean Chem. Soc. 2001, 22, 1019- 1022

${ }^{11}$ Miyata, S. Clays Clay Miner. 1983, 31, 305- 311

${ }^{12}$ Morioka, H.; Tagaya, H.; Karasu, M.; Kadokawa, J.; Chiba, K. Inorg. Chem. $1999,38,4211-4216$

${ }^{13}$ Avrami, M. J. Chem. Phys. 1940, 8, 212- 224

${ }^{14}$ Avrami, M. J. Chem. Phys. 1941, 9, 177- 184

${ }^{15}$ Francis, R. J.; O’Brien, S.; Fogg, A. M.; Halasyamani, P. S.; O'Hare, D. ; Loiseau, T.; Ferey, G. J. Am. Chem. Soc. 1999, 121, 1002- 1015

${ }^{16}$ Young, D. A.Decomposition of Solids. In The International Encyclopedia of Physical Chemistry and Chemical Physics, 21st ed.; Tompkins, F. C., Ed.;Pergamon Press Ltd: Oxford, 1966. Vol 1.

${ }^{17}$ Hancock, J. D.; Sharp, J. H. J. Am. Chem. Soc. 1972, 55, 74- 77

${ }^{18}$ Millange, F.; Walton, R. I.; O'Hare, D. J.Mater.Chem. 2000, 10, 1713- 1720

${ }^{19}$ Saitoh, H.; Machida, A.; Katayama, Y.; Aoki, K. Appl. Phys. Lett. 2009, 94, 151915

${ }^{20}$ Sperling, L. H.; Introduction to Physical Polymer Science, 4th ed.; John Wiley \& Sons: Hoboken, NJ, 2006; Chapter 6, pp 239- 323.

${ }^{21}$ Kandare, E.; Hossenlopp, J. M. J. Phys. Chem. B 2005, 109, 8469- 8475

${ }^{22}$ Khan, A. I.; O'Hare, D. J. Mater.Chem. 2002, 12, 3191- 3198

${ }^{23}$ Vyazovkin, S.; Wight, C. A. Annu. Rev. Phys. Chem. 1997, 48, 125- 149

${ }^{24}$ Vyazovkin, S. V.; Lesnikovich, A. I. Thermochim. Acta 1990, 165, 11- 15

Journal of Physical Chemistry A, Vol 114, No. 49 (December 16, 2010): pg. 12858-12869. DOI. This article is (C) American Chemical Society and permission has been granted for this version to appear in e-Publications@Marquette. American Chemical Society does not grant permission for this article to be further copied/distributed or hosted elsewhere without the express permission from American Chemical Society. 
NOT THE PUBLISHED VERSION; this is the author's final, peer-reviewed manuscript. The published version may be accessed by following the link in the citation at the bottom of the page.

${ }^{25}$ Vyazovkin, S.; Wight, C. A. Thermochim. Acta 1999, 340-341, 53- 68

${ }^{26}$ Vyazovkin, S. In The Handbook of Thermal Analysis \& Calorimetry; Brown, M. E.; Gallagher, P. K., Eds.; Recent Advances, Techniques and

Applications; Elsevier: Oxford, 2008; Vol. 5, pp 503- 538.

${ }^{27}$ Vyazovkin, S. Int. Rev. Phys. Chem. 2000, 19, 45- 60

${ }^{28}$ Vyazovkin, S.; Goryachko, V.; Bogdanova, V.; Guslev, V. Thermochim. Acta $1993,215,325-328$

${ }^{29}$ Budrugeac, P.; Homentcovschi, D.; Segal, E. J. Therm. Anal. Calorim. 2001, $63,457-463$

${ }^{30}$ Quaas, M.; Wulff, H.; Ivanova, O.; Helm, C. A. Z. Kristallogr. 2009, 241246

${ }^{31}$ Biswick, T.; Jones, W.; Pacula, A.; Serwicka, E.; Podobinski, J. J. Solid State Chem. 2007, 180, 1171- 1179

32Rajamathi, J. T.; Britto, S.; Rajamathi, M. J. Chem. Sci. 2005, 117, 629633

33Gaussian 98, Revision A.11.4. Frisch, M. J.; Trucks, G. W.; Schlegel, H. B.; Scuseria, G. E.; Robb, M. A.; Cheeseman, J. R.; Zakrzewski, V. G.; Montgomery, J A. Jr.; Stratmann, R. E.; Burant, J. C.; Dapprich, S.; Millam, J. M.; Daniels, A. D.; Kudin, K. N.; Strain, M. C.; Farkas, O.; Tomasi, J.; Barone, V.; Cossi, M.; Cammi, R.; Mennucci, B.; Pomelli, C.; Adamo, C.; Clifford, S.; Ochterski, J.; Petersson, G. A.; Ayala, P. Y.; Cui, Q.; Morokuma, K.; Rega, N.; Salvador, P.; Dannenberg, J. J.; Malick, D. K.; Rabuck, A. D.; Raghavachari, K.; Foresman, J. B.; Cioslowski, J.; Ortiz, J. V.; Baboul, A. G.; Stefanov, B. B.; Liu, G. ; Liashenko, A.; Piskorz, P.; Komaromi, I.; Gomperts, R.; Martin, R. L.; Fox, D. J.; Keith, T.; Al-Laham, M. A.; Peng, C. Y.; Nanayakkara, A.; Challacombe, M.; Gill, P. M. W.; Johnson, B.; Chen, W.; Wong, M. W.; Andres, J. L.; Gonzalez, C.; Head-Gordon, M.; Replogle, E. S.; Pople, J. A., Gaussian, Inc., Pittsburgh PA, 2002.

${ }^{34}$ Powder Diffraction File. Andrews, L. C.; Bernstein, L. R.; Foris, C. M.; McClune, W. F.; Rendle, D. F.; Rohrman, A. C.; Rotella, F. J.; Ryba, E.; Wallace, P. L. Alphabetical Indexes for Experimental Pattern. Set 1-59 International Centre for Diffraction Data, Inorganic Phases: Newtown Square, 2009.

${ }^{35}$ Pecharsky, V. K.; Zavalij, P. Y. Fundamentals of Powder Diffraction and Structural Characterization of Materials; Kluwer Academic Publishers: Boston, MA, 2001; Chapter 2, pp 100- 260.

${ }^{36}$ Pereira, D. C.; de Faria, D. L. A.; Constantino, V. R. L. J. Brazil. Chem. Soc. $2006,17,1651-1657$

${ }^{37}$ Addison, C. C.; Gatehouse, B. M. J. Chem. Soc. 1960, 613- 616

${ }^{38}$ Rabu, P.; Drillon, M.; Hornick, C. Analusis 2000, 28, 103- 108

${ }^{39}$ Prasanna, S. V.; Kamath, P. V. J. Colloid Interface Sci. 2009, 331, 439- 445

${ }^{40}$ Jimenez-Lopez, A.; Rodriguez-Castellon, E.; Olivera-Pastor, P.; MairelesTorres, P.; Tomlinson, A. A. G.; Jones, D. J.; Roziere, J. J. Mater. Chem. 1993, 3, 303- 307

${ }^{41}$ Jambor, J. L.; Dutrizac, J. E.; Roberts, A. C.; Grice, J. D.; Szymanski, J. T. Can. Mineral. 1996, 34, 61- 72

${ }^{42}$ Baerlett, N.; McQuillan, B. W. In Intercalation Chemistry, Materials Science Series; Whittingham, M. S.; Jacobson, A. J., Eds.; Academic Press: New York, 1982; Chapter 2, pp 19- 98.

Journal of Physical Chemistry A, Vol 114, No. 49 (December 16, 2010): pg. 12858-12869. DOI. This article is @ American Chemical Society and permission has been granted for this version to appear in e-Publications@Marquette. American Chemical Society does not grant permission for this article to be further copied/distributed or hosted elsewhere without the express permission from American Chemical Society. 
NOT THE PUBLISHED VERSION; this is the author's final, peer-reviewed manuscript. The published version may be accessed by following the link in the citation at the bottom of the page.

${ }^{43}$ Williams, G. R.; O'Hare, D. Chem. Mater. 2005, 17, 2632- 2640

${ }^{44}$ Solin, S. A. J. Mol. Catal. 1984, 27, 293- 303

${ }^{45}$ Solin, S. A. Annu. Rev. Mater. Sci. 1997, 27, 89- 115

${ }^{46}$ Fogg, A. M.; Dunn, J. S.; O'Hare, D. Chem. Mater. 1998, 10, 356- 360

${ }^{47}$ Iyi, N.; Kurashima, K.; Fujita, T. Chem. Mater. 2002, 14, 583- 589

${ }^{48}$ Williams, G. R.; Norquist, A. J.; O'Hare, D. Chem. Mater. 2004, 16, 975981

${ }^{49}$ Williams, G. R.; Fogg, A. M.; Sloan, J.; Taviot-Gueho, C.; O'Hare, D. Dalton Trans. 2007, 3499- 3506

${ }^{50}$ Ragavan, A.; Khan, A.; O'Hare, D. J. Mater. Chem. 2006, 16, 4155- 4159

${ }^{51}$ Miladinovic, Z.; Zakrzewska, J.; Kovacevic, B.; Bacic, G. Mater. Chem. Phys. 2007, 104, 384- 389

${ }^{52}$ Williams, G. R.; Dunbar, T. G.; Beer, A. J.; Fogg, A. M.; O'Hare, D. J. Mater. Chem. 2006, 16, 1222- 1230

${ }^{53}$ Mckelvy, M. J.; Sharma, R.; Glaunsinger, W. S. Solid State Ionics 1993, $63-5,369-377$

${ }^{54}$ McKelvy, M.; Sidorov, M.; Marie, A.; Sharma, R.; Glaunsinger, W. Chem. Mater. 1994, 6, 2233- 2245

55Johnsen, R. E.; Krumeich, F.; Norby, P. J. Appl. Crystallogr. 2010, 43, 434447

${ }^{56}$ Evans, J. S. O.; Price, S. J.; Wong, H. V.; O'Hare, D. J. Am. Chem. Soc. $1998,120,10837-10846$

57Williams, G.; Khan, A.; O'Hare, D. In Layered Double Hydroxides: Structure and Bonding 119; Duan, X.; Evans, D. G., Eds; Springer: Berlin Heidelberg:, 2006; pp 161- 192.

${ }^{58}$ Taviot-Gueho, C.; Feng, Y.; Faour, A.; Leroux, F. Dalton Trans. 2010, 39, 5994- 6005

${ }^{59}$ Pilling, M. J.; Seakins, P. W. Reaction Kinetics; Oxford University Press: New York, 1995.

${ }^{60}$ Ho, Y. S.; Ng, J. C. Y.; Mckay, G. Sep. Purif. Methods 2000, 29, 189- 232

${ }^{61}$ Haque, R.; Lindstrom, F. T.; Freed, V. H.; Sexton, R. Environ. Sci. Technol. $1968,2,207-211$

${ }^{62}$ Lv, L.; He, J.; Wei, M.; Evans, D. G.; Zhou, Z. L. Water Res. 2007, 41, $1534-1542$

${ }^{63}$ ten Hulscher, T.; Cornelissen, G. Chemosphere 1996, 32, 609- 626

${ }^{64}$ Ragavan, A.; Khan, A. I.; O'Hare, D. J.Mater.Chem. 2006, 16, 602- 608

${ }^{65}$ Fujita, W.; Awaga, K.; Yokoyama, T. Inorg. Chem. 1997, 36, 196- 199

${ }^{66}$ Braithwaite, R. S. W.; Mereiter, K.; Paar, W. H.; Clark, A. M. Mineral. Mag. $2004,68,527-539$

${ }^{67}$ Acrivos, J. V. In Intercalated Layered Materials; Lévy, F., Ed.; D. Reidel Publishing Company: Dordrecht, 1979; Chapter 1, pp 33- 98.

\section{Supporting Information}

Journal of Physical Chemistry A, Vol 114, No. 49 (December 16, 2010): pg. 12858-12869. DOI. This article is (C) American Chemical Society and permission has been granted for this version to appear in e-Publications@Marquette. American Chemical Society does not grant permission for this article to be further copied/distributed or hosted elsewhere without the express permission from American Chemical Society. 


\title{
Supporting Information
}

for

\section{Anion Exchange Kinetics of Nanodimensional Layered Metal Hydroxides: Use of Isoconversional Analysis}

\author{
Stephen Majoni, Jeanne M. Hossenlopp* \\ Department of Chemistry \\ Marquette University, P.O. Box 1881 \\ Milwaukee, WI 53201-1881
}

*Corresponding author. Tel.; +1 414288 3537; fax: + 14142887066.

E-mail: Jeanne.hossenlopp@marquette.edu 


\section{CONTENTS}

Table S1: Summary of elemental analysis data.

Figure S1: Representative UV spectra collected during the release of $\mathrm{Cn}$ and o-HCn.

Figure S2: TG (b) and DTG (a) curves for (A) C-o-HCn and (B) BCN.

Figure S3: TG (b) and DTG (a) curves for (A) ZC-Ac and (B) ZC-Cn, in nitrogen atmosphere at a ramp rate of $20 \%$ min.

Figure S4: XRD profile of C-o-HCn exchanged with chloride.

Figure S5: Double-logarithmic plots for the exchange reaction of $\mathrm{Cl}^{-}$anion and $\mathrm{C}-\mathrm{o}-\mathrm{HCn}$ at various temperatures for solution analysis.

Figure S6. Arrhenius plots for the determination of the activation energy for (I) the release of o- $\mathrm{HCn}$ from C-o-HCn for (A) solid state analysis, (B) solution analysis and (II) for the release of Cn from ZC-Cn (C) solid state analysis and (D) solution analysis

Figure S7. Released [Cn] as a function of time highlighting the period of slow and linear accumulation of $\mathrm{Cn}$ anions.

Figure S8: XRD profile of ZC-Cn exchanged with chloride.

Figure S9: Double-logarithmic plots for the exchange reaction of $\mathrm{Cl}^{-}$anion and $\mathrm{ZC}-\mathrm{Cn}$ at various temperatures for A) solid state analysis and (B) solution analysis: 
Table S1: Summary of elemental analysis data.

\begin{tabular}{llllll}
\hline & \multicolumn{5}{c}{ Elemental analysis: experimental (calculated) } \\
\cline { 2 - 6 } Compound & $\% \mathrm{~N}$ & $\% \mathrm{Zn}$ & $\% \mathrm{Cu}$ & $\% \mathrm{H}$ & $\% \mathrm{C}$ \\
\hline $\mathrm{Cu}_{2.3}(\mathrm{OH})_{3.6}\left(\mathrm{NO}_{3}\right)$ & $4.98(5.13)$ & 0.00 & $52.56(54.28)$ & $1.34(1.37)$ & $<0.03$ \\
$\mathrm{Cu}_{2.0}(\mathrm{OH})_{2.9}(\mathrm{O}-\mathrm{HCn})_{1.1} 0 \cdot 6 \mathrm{H}_{2} \mathrm{O}$ & $<0.03$ & 0.00 & $36.61(35.64)$ & $3.24(3.25)$ & $32.94(32.66)$ \\
$\mathrm{ZnCu}_{2.8}(\mathrm{OH})_{5.3}(\mathrm{Ac})_{1.7} \cdot 2.6 \mathrm{H}_{2} \mathrm{O}$ & 0.00 & $14.72(14.15)$ & $35.84(34.44)$ & $3.25(3.39)$ & $9.25(8.90)$ \\
$\mathrm{ZnCu}_{3.2}(\mathrm{OH})_{6.1}(\mathrm{Cn})_{2.4}$ & 0.00 & $8.81(9.06)$ & $27.8(28.57)$ & $3.00(3.08)$ & $35.14(36.11)$ \\
\end{tabular}

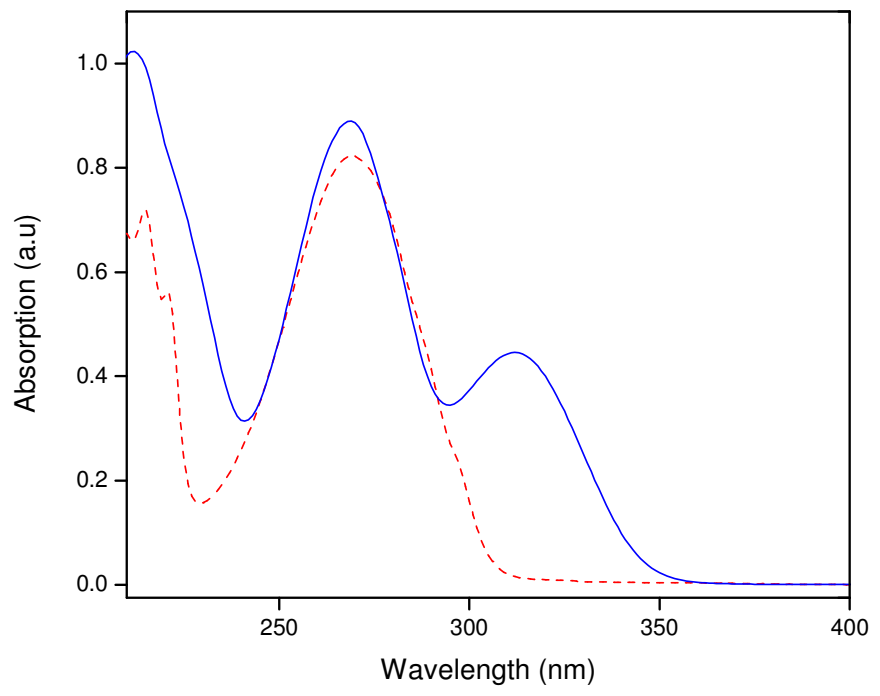

Figure S1: Representative UV spectra collected during the release of $\mathrm{Cn}(---)$ and o- $\mathrm{HCn}(-)$. 

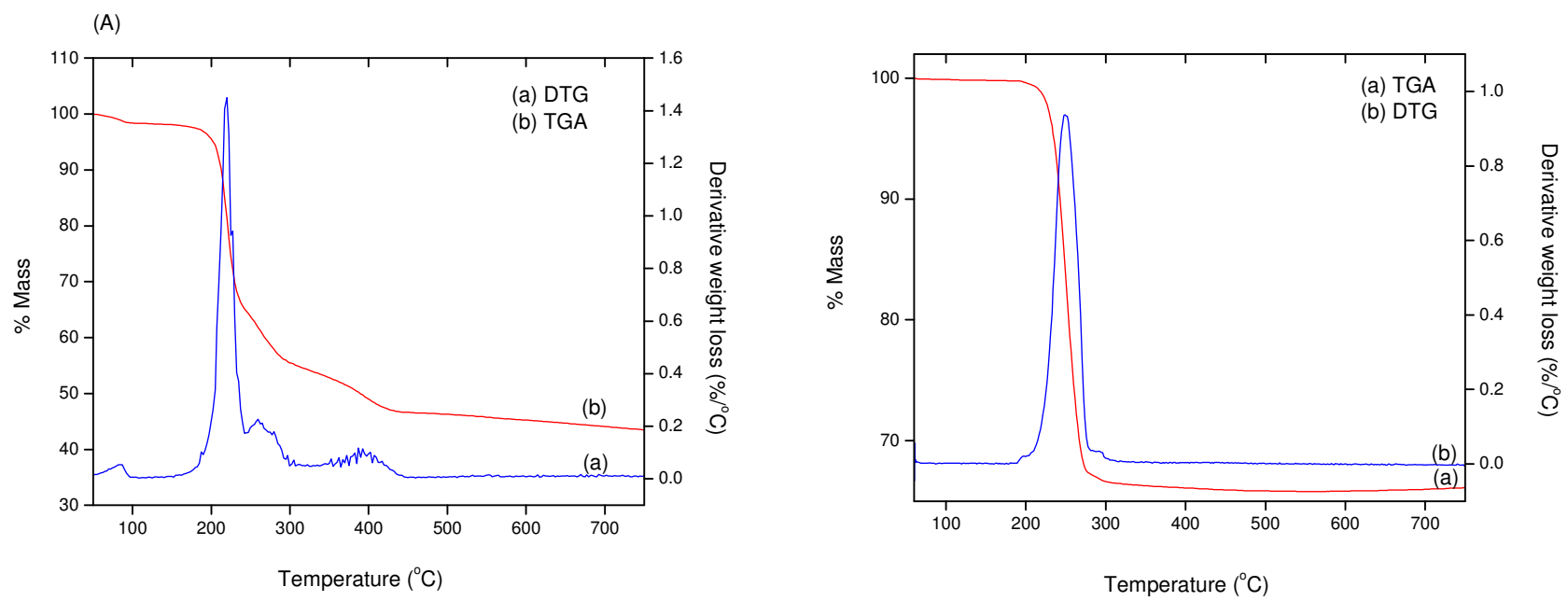

Figure S2: TG (b) and DTG (a) curves for (A) C- $o-\mathrm{HCn}$ and (B) BCN, in nitrogen atmosphere at a ramp rate of $20 \%$ min.
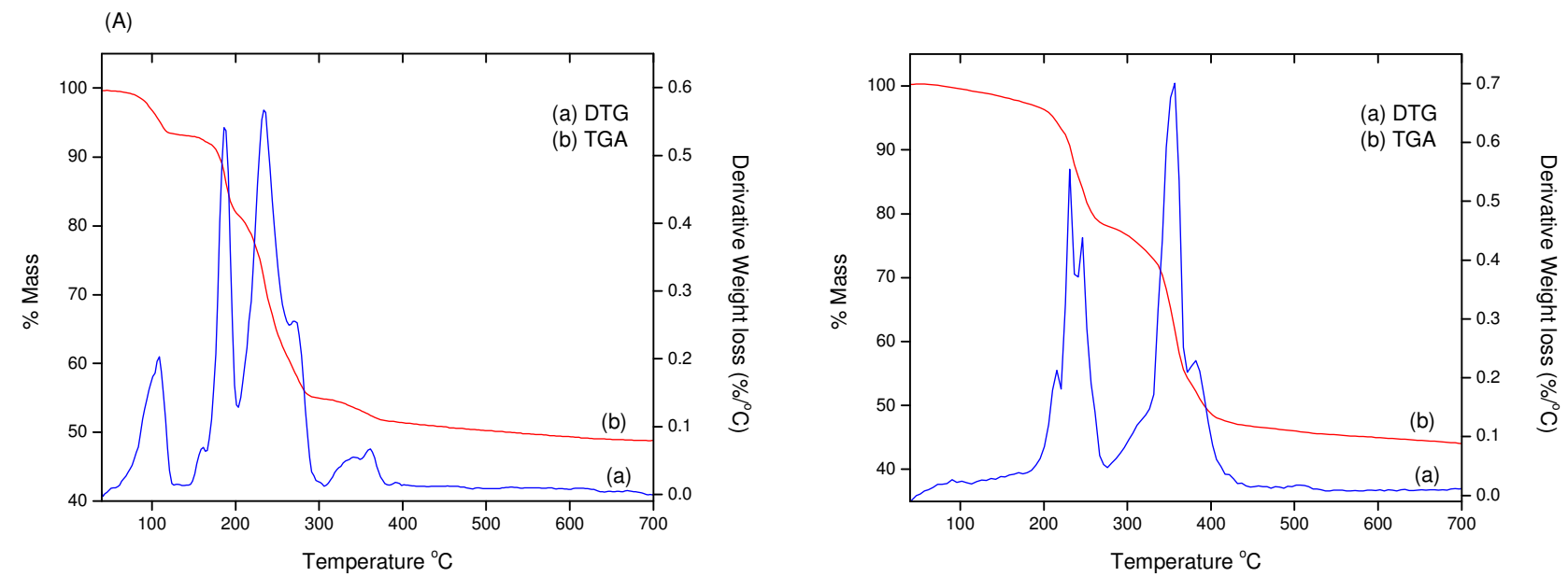

Figure S3: TG (b) and DTG (a) curves for (A) ZC-Ac and (B) ZC-Cn, in nitrogen atmosphere at a ramp rate of $20 \%$ min 


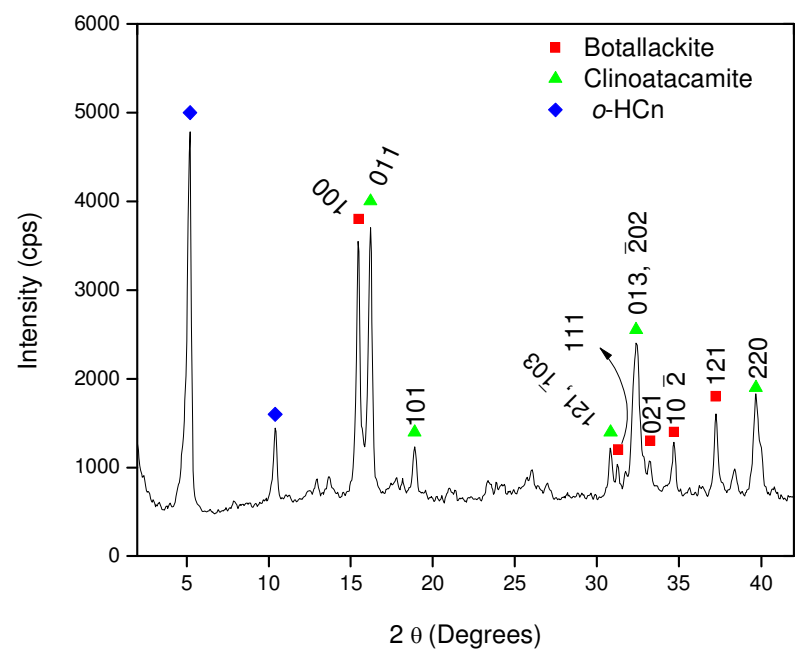

Figure S4: XRD profile of C-o-HCn exchanged with chloride for 60 minutes at $60^{\circ} \mathrm{C}$. O-HCn phase is represented by closed diamonds, botallackite phase by closed squares [PDF\# 58-520] and clinoatacamite phase by closed triangles [PDF\# 50-1559].

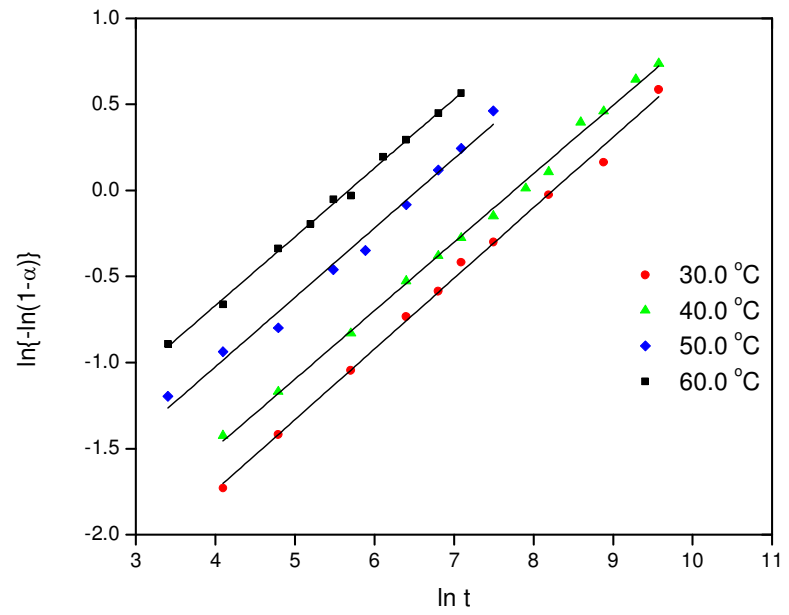

Figure S5: Double-logarithmic plots for the exchange reaction of $\mathrm{Cl}^{-}$anion and $\mathrm{C}-\mathrm{o}-\mathrm{HCn}$ at various temperatures for solution analysis: $60^{\circ} \mathrm{C}(\bullet), 50^{\circ} \mathrm{C}(\bullet), 40^{\circ} \mathrm{C}(\Delta), 30^{\circ} \mathrm{C}(\bullet)$. 
(A)
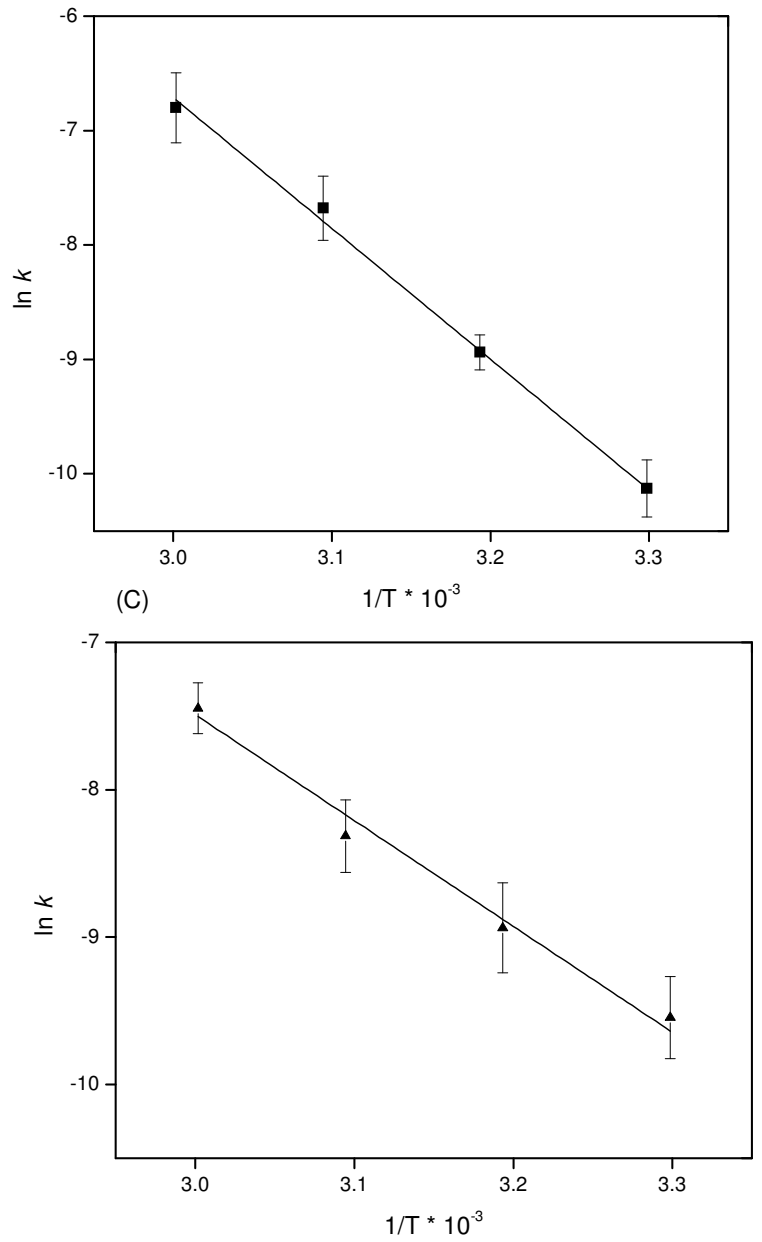

(B)
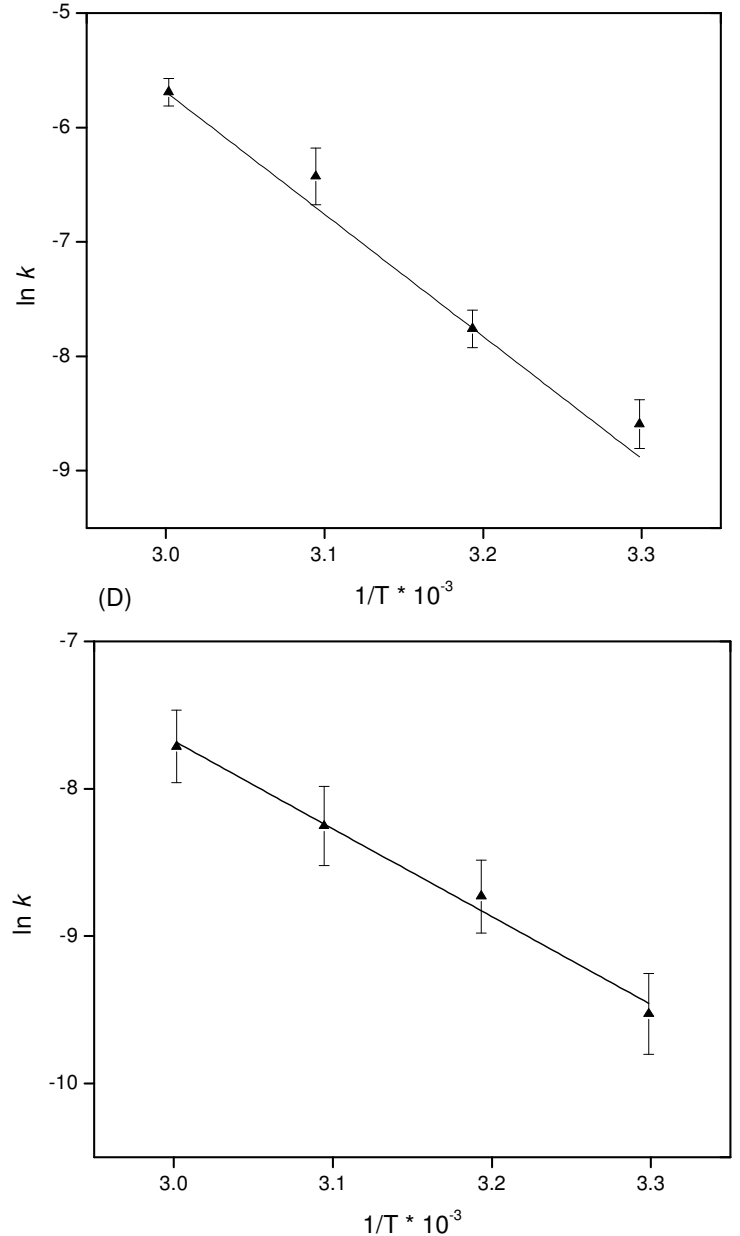

Figure S6. Arrhenius plots for the determination of the activation energy for (I) the release of o- $\mathrm{HCn}$ from C-o-HCn for (A) solid state analysis, (B) solution analysis and (II) for the release of $\mathrm{Cn}$ from $\mathrm{ZC}-\mathrm{Cn}$ (C) solid state analysis and (D) solution analysis 


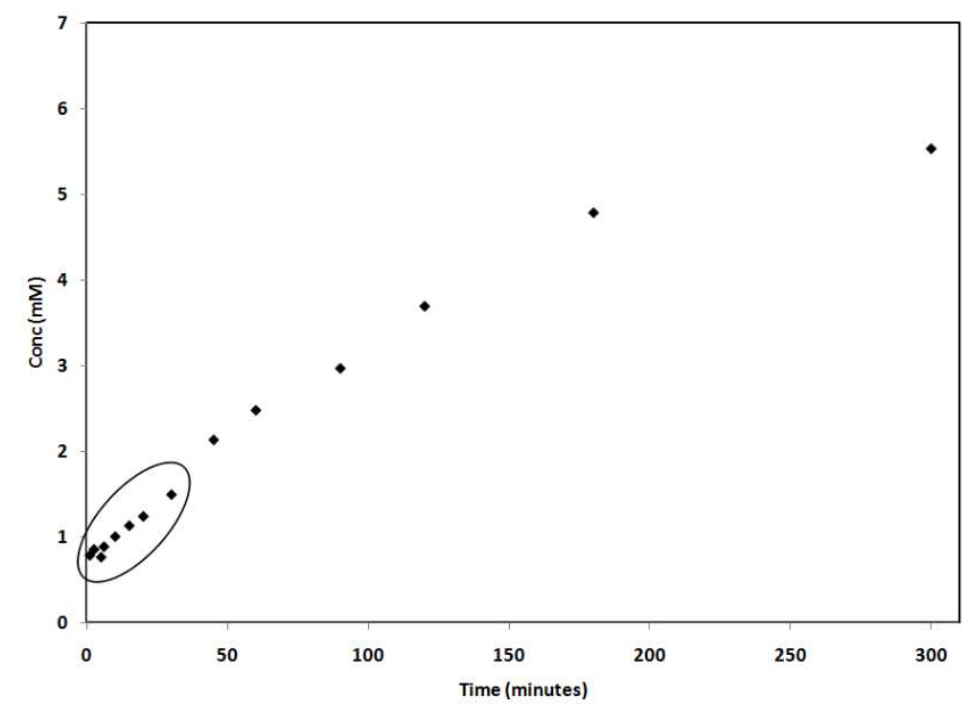

Figure S7. Released $[\mathrm{Cn}]$ as a function of time highlighting the period of slow and linear accumulation of $\mathrm{Cn}$ anions.

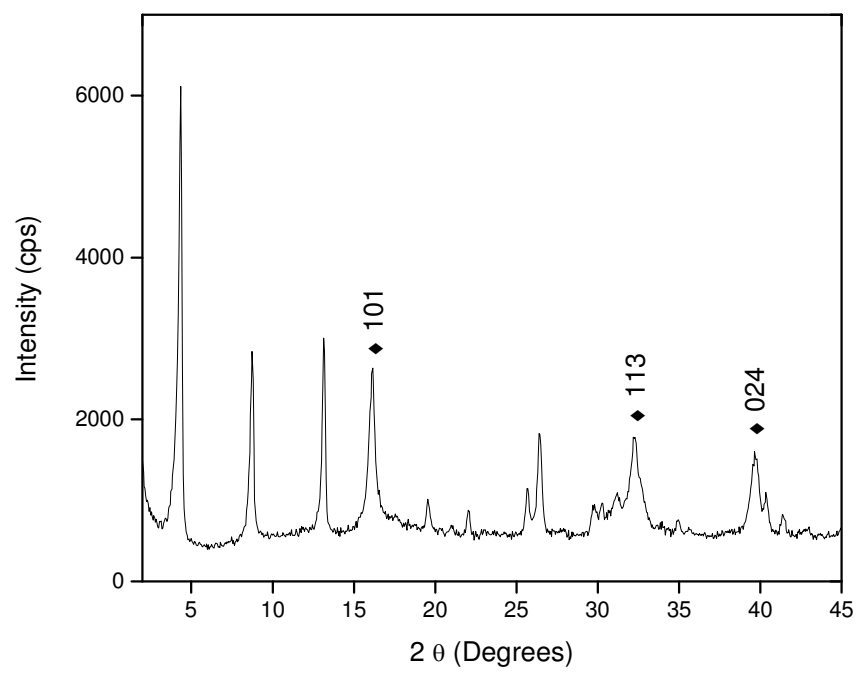

Figure S8: XRD profile of ZC-Cn exchanged with chloride for 60 minutes at $50^{\circ} \mathrm{C}$. Chloride phase has been indexed as paratacamite represented by closed triangles [PDF\# 50-1558]. 

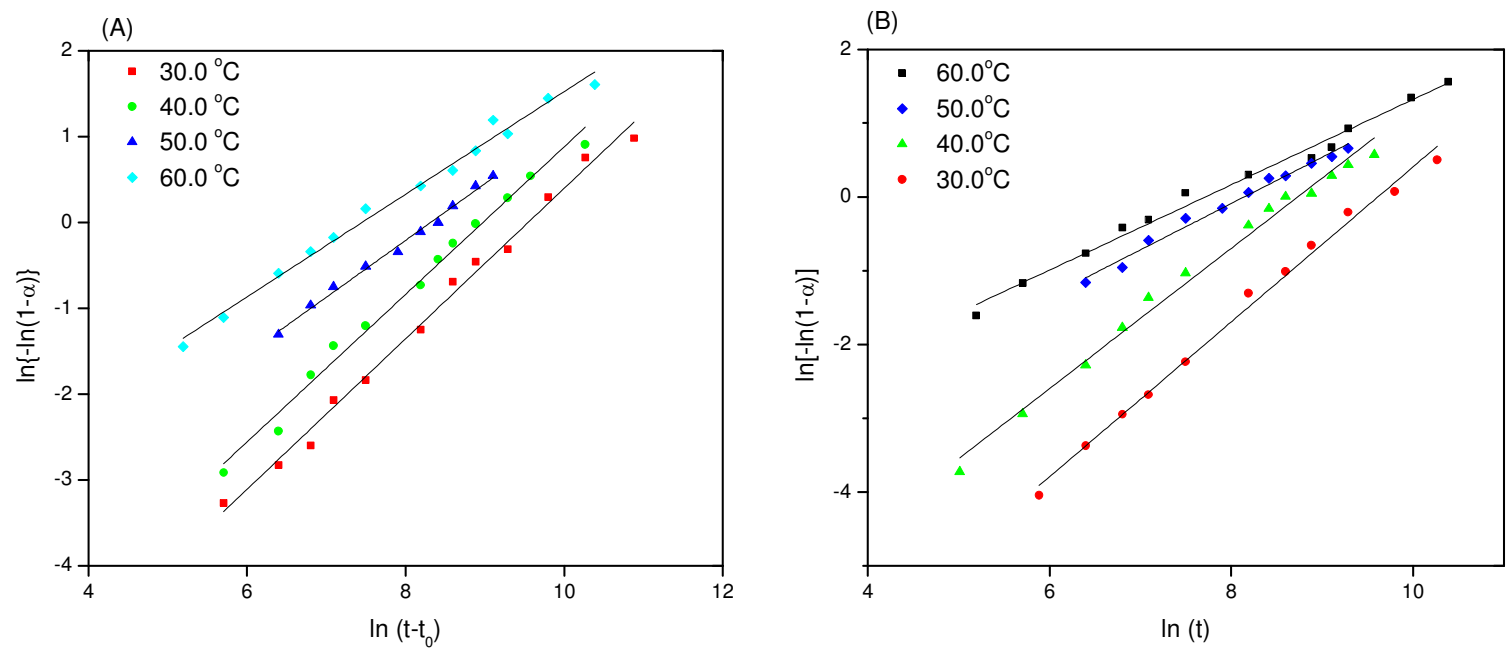

Figure S9: Double-logarithmic plots for the exchange reaction of $\mathrm{Cl}^{-}$anion and $\mathrm{ZC}-\mathrm{Cn}$ at various temperatures for A) solid state analysis and (B) solution analysis: $60^{\circ} \mathrm{C}(\bullet), 50^{\circ} \mathrm{C}(\bullet), 40{ }^{\circ} \mathrm{C}(\Delta), 30^{\circ} \mathrm{C}(\bullet)$. 